\title{
Membracidae colombianae. Revisión de las especies colombianas del género Membracis
}

\author{
Leopoldo Richter
}

Rev. Acad. Colomb. Cienc. Ex. Fis. Nat. 1947, 8 (27): 382-403.

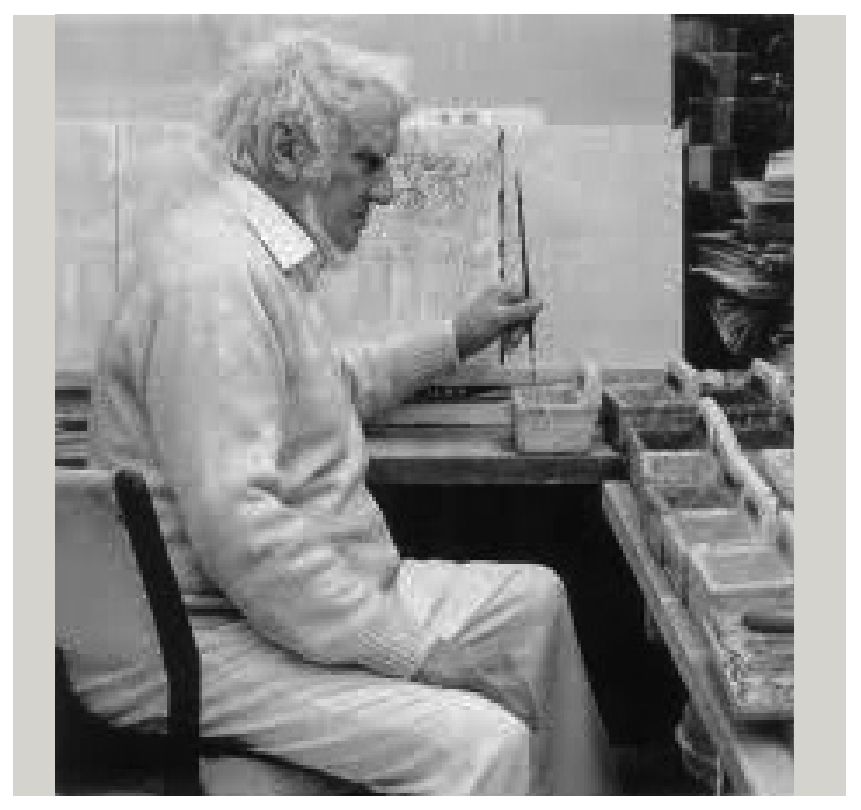

\section{Leopoldo Richter (1896-1984)}

La rica fauna tropical ha sido un imán para muchos naturalistas y exploradores foráneos, algunos de ellos tan famosos como Darwin, Wallace y Bates. A esta fascinación no pudo escapar el entomólogo, naturalista y artista Leopoldo Richter, de quien hace poco alguien dijo adecuadamente "Lo suyo fue el cruce de dos universos, el del arte y el de la naturaleza”. Leopoldo Richter fue, además, un agudo observador de la naturaleza como un todo, el que incluía desde los diminutos insectos objeto de su estudio y pasión, hasta los paisajes y los habitantes de las selvas y sabanas, los cuales exploró hacia la mitad del siglo pasado en su nueva patria. Richter llega a Colombia en 1935 para no abandonarla nunca, seducido como estaba por la exuberancia de bosques, ríos, animales y pueblos de un país cuya exploración apenas comenzaba y donde, incluso, llegar a los Llanos podría convertirse en una odisea. Su visión de la naturaleza y sus técnicas de dibujo y pintura, acompañadas por el trasfondo del ejercicio académico en la Universidad Nacional de Colombia, fueron el entramado perfecto para sus acercamientos a la riqueza de formas y colores de los insectos en los trópicos.
Los membrácidos constituyen uno de los grupos de insectos más interesantes de los trópicos del mundo. Comprenden una familia natural dentro de los Auchenorrhyncha, división de Hemiptera (cochinillas, cigarras, chinches), agrupación que comprende muchas formas adaptadas para alimentarse de las plantas gracias a sus aparatos bucales especializados. Los membrácidos poseen varias tácticas para evadir enemigos, como son el asociarse con hormigas o disfrazarse como espinas de plantas. Algo que ha llamado la atención de naturalistas desde el siglo XIX es la rica variedad de prolongaciones dorsales del pronoto (la parte más anterior del tórax) que desafía al más imaginativo de los biólogos; de hecho, para algunos entomólogos este es un ejemplo de evolución sin control. Los tamaños, formas y colores de tales prolongaciones no podrían pasar desapercibidos al ojo del académico y artista Leopoldo Richter, quien en esta ya clásica publicación ofreció una sinopsis de las 20 especies entonces conocidas del género Membracis, varias de ellas nuevas para la ciencia y que fueran recolectadas en localidades de los Llanos, el Amazonas y la Cordillera Oriental. Para cada especie se ofrece información individual para inmaduros y adultos, excelentes dibujos en blanco y negro (algunos en láminas a color), información de hábitat (altura, tipo de paisaje, asociación con plantas), notas comparativas entre especies y localidades, etc. Si bien el lenguaje de la época dista del árido y monótono de las revisiones actuales, las observaciones y dibujos son suficientes para entender la variedad de esta familia tropical. Y de una u otra forma Richter abrió las puertas para investigaciones futuras; de Membracidae sabemos que sólo en Colombia hay unos 116 géneros y casi 500 especies.

Fernando Fernández, Ph. D. Instituto de Ciencias Naturales Universidad nacional de Colombia 


\section{MEMBRACIDAE COLOMBIANAE REVISION DE LAS ESPECIES COLOMBIANAS DEL GENERO MEMBRACIS}

Del Serviclo de Entomologia del instituto de Clencias Naturales de la Universidad Nacional de Colombia - Bogotá.

La presente descripción de las especies colombianas del género Membracis se refiere, principalmente, al ambiente natural.

Con tal fin se han escogido, para observaciones y recolección, tres regiones típicas de la zona caliente, con regiones adyacentes templadas, es decir, regiones de mayor altitud (1.000-1.800 metros) donde se encuentran todavía especies de este género. Tales regiones son:

$1^{\text {a }}$ Los Llanos orientales alrededor del río Meta (tierra caliente: 450-390 metros), inclusive las estribaciones de la Cordillera Oriental (tierra templada) hacia el sur los ríos Humadea y Guamal, y el río Casanare hacia el norte.

$2^{\text {a }}$ La ladera occidental de la Cordillera Oriental hacia las llanuras de los ríos Opón, Carare y Magdalena (alrededor de 10 s 400 a 300 metros). Sobre la misma latitud como en la región anterior.

$3^{\text {a }}$ La regín del río Amazonas, desde Leticia hasta Loreto-Yacu en dirección occidental, y hacia el norte al río Cotuhé. Distinta latitud pero poca diferencia de longitud, como en las dos anteriores regiones.

Las dos primeras regiones mencionadas tienen condiciones climáticas muy parecidas, pero altas cumbres de la cordillera impiden completamente el traspaso de todas las especies tropicales del género Membracis. Tampoco hay posibilidades de rodeo ni por el norte ni por el sur.

En cambio, no está obstaculizada la comunicación entre el Amazonas y los Llanos orientales.

Aunque todas estas regiones muestren una base común como punto de salida en el desarrollo de todas las especies, la existencia de formas absolutamente distintas en su forma de aparición en el valle del Magdalena y en los Llanos orientales y Amazonas señala el camino distinto que ha tomado la formación de estas especies en cada uno de dichos lugares.

Las formas de apariencia de este género, del río Amazonas, se distinguen en algunos detalles de las de los Llanos. Pero estas diferencias tienen sus reglas y no s6́lo se limitan en los Membracidos (1).

(1) En la región del Amazonas se nota en muchas familias de insectos una cierta diferencia en extensión e intensidad del colorido, sin cambio alguno en el carácter del dibujo. Es decir, este dibujo puede mostrar claramente dos formas distintas de expresión: primera, su tamaño en proporción con el área de la superficie invariable del fondo.

Siempre y cuando que en Membracis tectigera se está ensanchando de modo esencial y constante la mancha central en proporción con el área total del apéndice, el color de esta mancha trata de desalojar el colorido original del apéndice; y segunda, el aumento de la intensidad del color: si se presenta también tales influencias basadas en un cambio del ambiente un aumento de la intensidad del color, se establece cierta dirección en el desarrollo de los colores.

En el primer caso: en la región inmediata a las orillas del río Amazonas, $M$. tectigera tiene manchas más anchas sin que se ensanche la franja frontal. (Fig. 1. Membracis tectigera Stoll $o$, de los Llanos orientales, cerca de Villavicencio; vive en Vismia beccifera (L.) Tr. et P1.

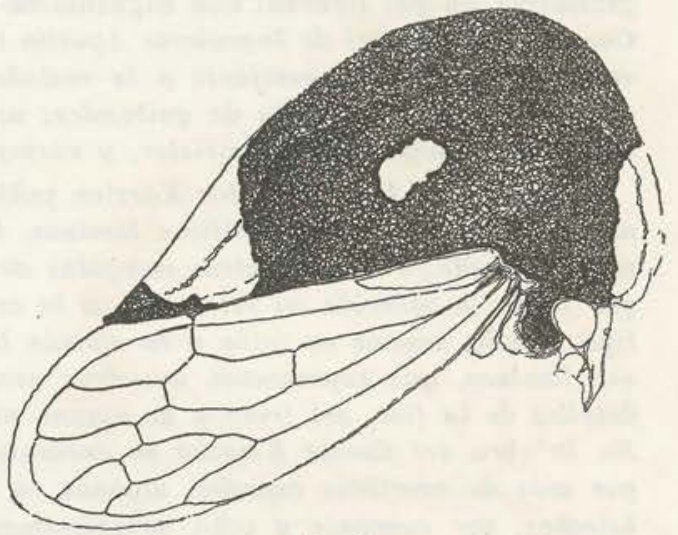

Fig. 1.

Fig. 2. Membracis tectigera Stoll $\hat{o}+q+$ larva, del río Tacana de la región amazónica sobre Vismia beccifera (L.) Tr. et Pl.).

En el segundo caso: el color, generalmente gris-blanco o gris-amarillo, no se vuelve más oscuro o más amarillo sino que pasa a un blanco tan brillante y puro, que hace necesario mezclar un color blanco con azul para lograr su reproducción gráfica.

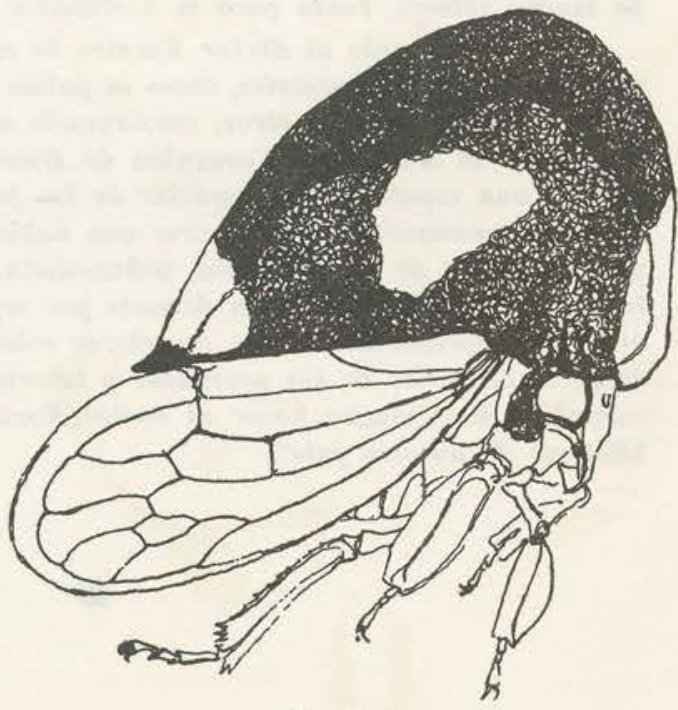

Fig. 2 ช 


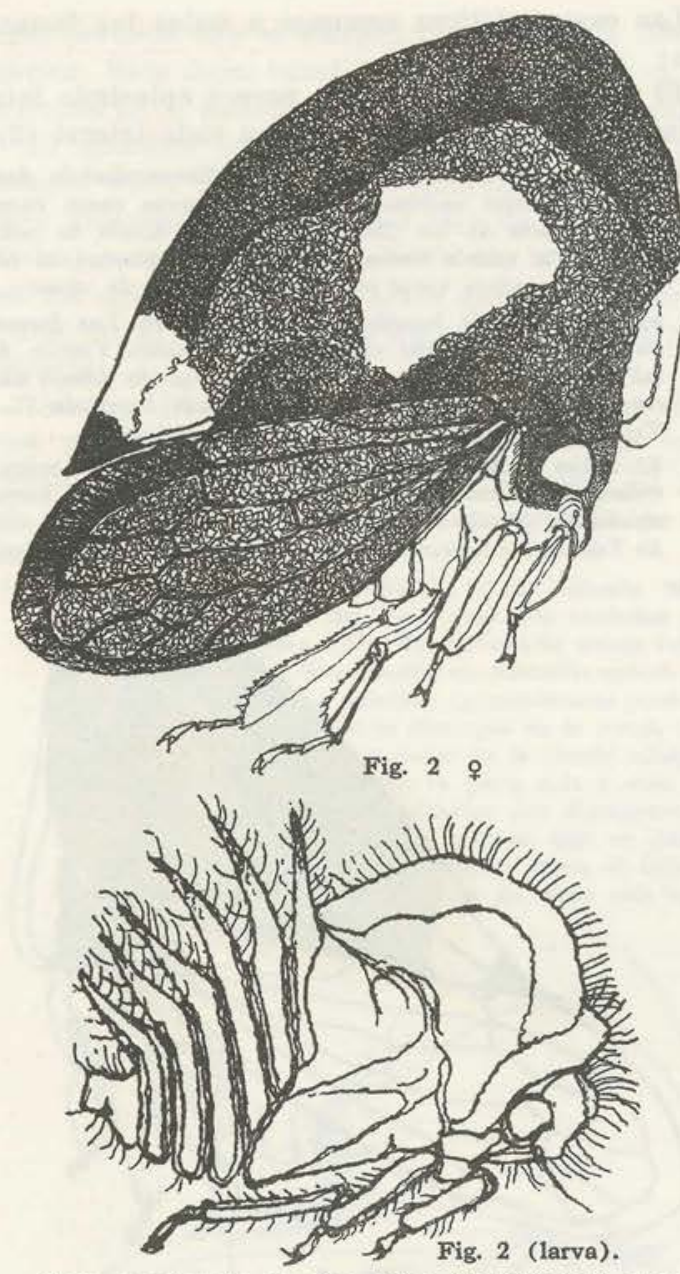

Como un ejemplo de otro orden (Lepidóptera) menciono la Dinia mena Hbn. (Euchromidae) (Fig. 3). Las figuras muestran claramente un aumento proporcional de todas las áreas negras en sus alas, si la larva ha vivido en un clima de creciente humedad. (Véanse las figuras a) ejemplar de Caño Grande, Meta, y b) de Leticia,
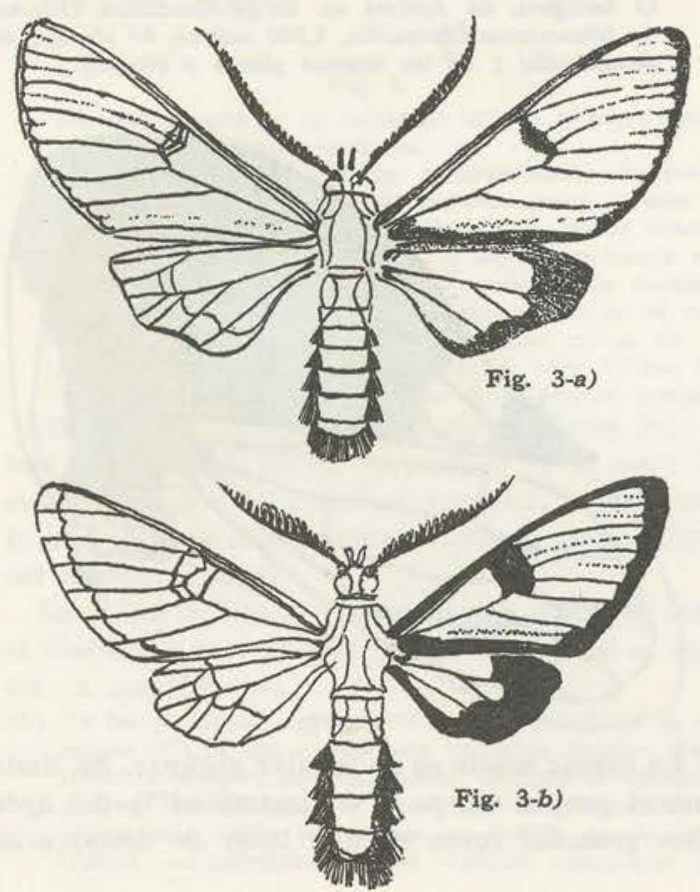

Amazonas). Las larvas de estas regiones, tan distintas en clima, viven siempre de las mismas plantas (gramíneas); no ha sido posible constatar diferencias on las larvas, como tampoco en la actitud extraña que presentan durante su crisalidación. Igualmente puede constatarse en Hystiaea bellatrix Wkr. toda una escala de coloridos crecientes y menguantes al mismo tiempo, lo que depende de si los ejemplares provienen del norte (Meta) que es más bien seco, o del sur que es húmedo. Análogamente, los colores también varían, si se trata de cambios típicos en el clima dentro de cierto distrito (Fig. 4: a) selva de los Llanos orientales (Meta); b) selva al pie de la Cordillera Oriental (llueve casi diariamente); c) Río Orteguaza, Putumayo (Tres Esquinas), y $d$ ) río Tacana, Amazonas.

El fondo de las alas es de color negro, las manchas (punteadas en el dibujo) de color amarillo, y las negras, de color rojo.

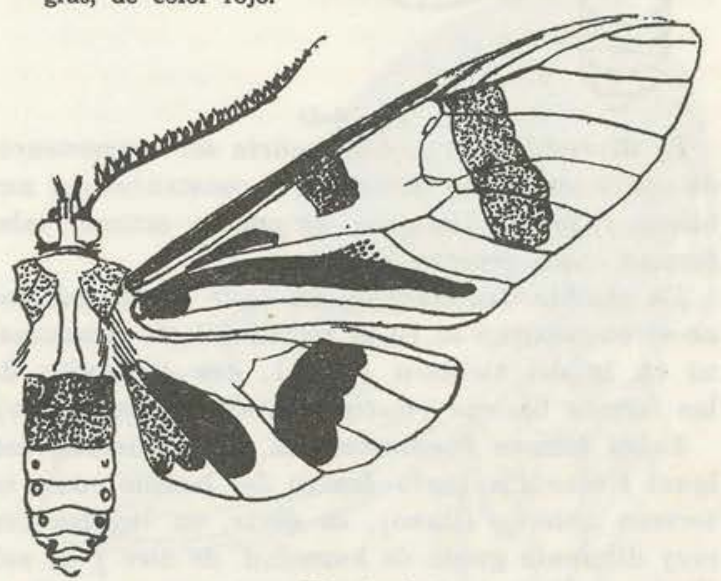

Fig. 4-a)

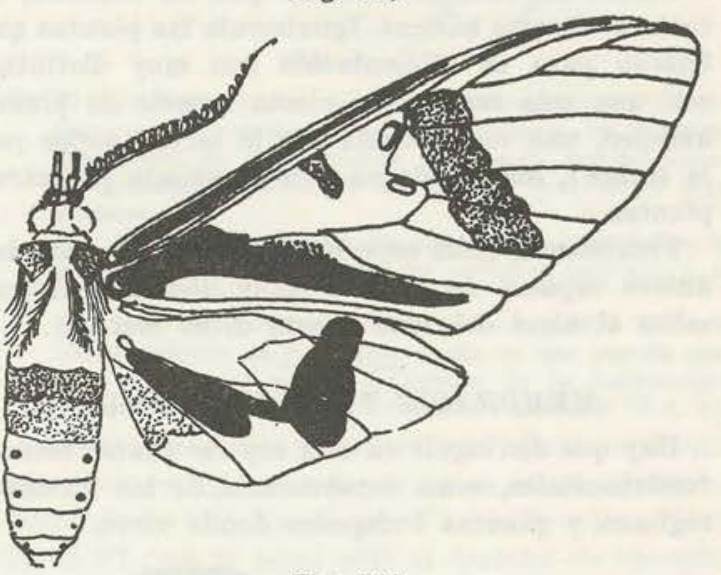

Fig. 4-b)

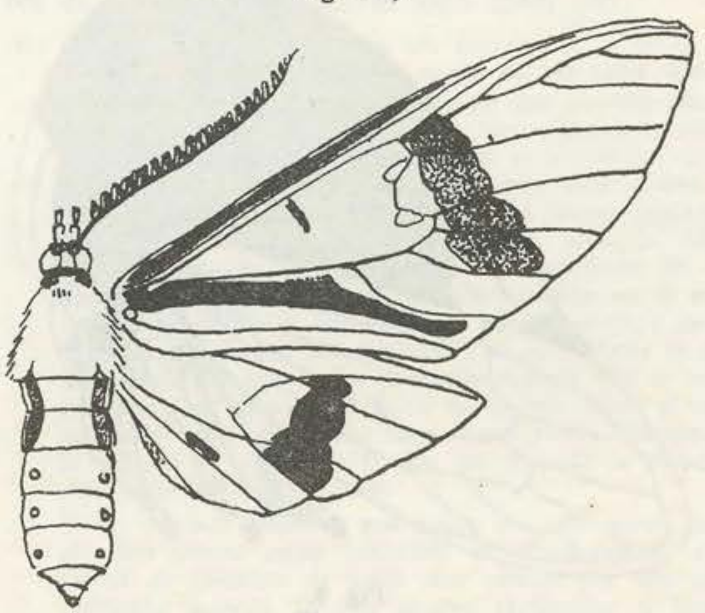

Fig. 4-c) 


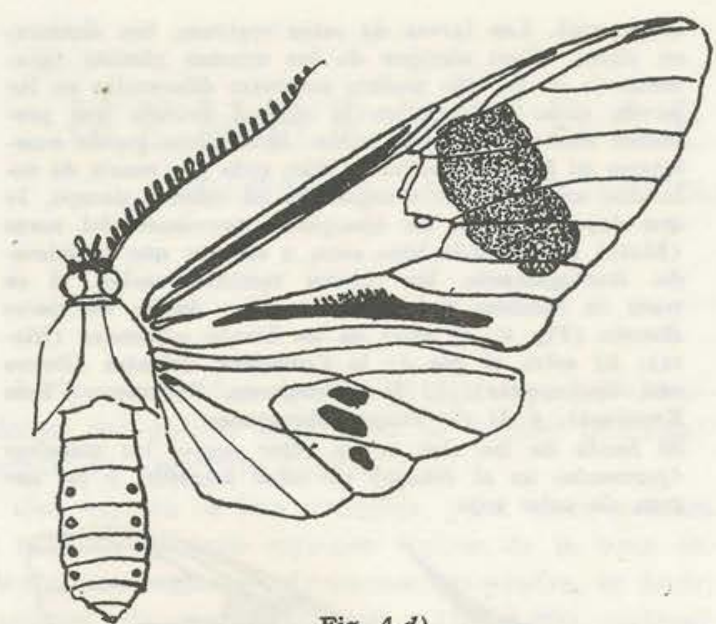

Fig. 4-d)

La diversidad de colores podría ser consecuencia de condiciones muy definidas y constantes del ambiente $y$, por lo tanto, no se pueden estimar tales formas como especies distintas.

En cambio, las especies del valle del Magdalena no se encuentran ni en la región del río Amazonas ni en la del Orinoco (Meta), con excepción de las formas básicas (tectigera-elevata y mexicana).

Estas formas fundamentales viven además, con igual frecuencia tanto dentro del bosque como en terreno abierto (llano), es decir, en lugares con muy diferente grado de humedad de aire y de sol. Factores diversos demuestran que, en realidad, se trata de formas básicas. Igualmente las plantas que buscan para su alimentación son muy distintas, con una sola regla: que cierta especie de planta huésped, una vez escogida por la larva (mejor por la madre), más tarde no será cambiada por otras plantas.

Finalmente, estas especies fundamentales son las únicas capaces de vivir en muy distintas alturas sobre el nivel del mar (hasta 2.100 metros).

\section{MEMBRACIS TECTIGERA Stoll.}

Hay que distinguir en esta especie cuatro formas fundamentales, como consecuencia de las distintas regiones y plantas huéspedes donde viven.

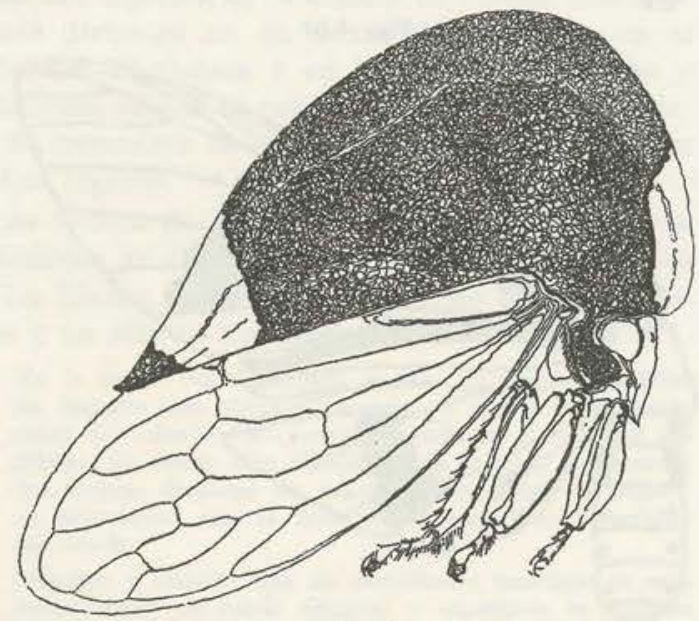

Fig. 5.
Las características comunes a todas las formas son:

El apéndice pronotal, que parece aplastado lateralmente, tiene forma de casco en vista lateral (2).

(2) Varía mucho esta forma de casco. Encontrándola dentro del mismo ambiente, puede estimarse como cause la diferencia de las plantas huéspedes donde se halla siempre la misma variedad, aunque las plantas se encuentren muchas veces muy distantes unas de otras:

a) Sobre Vismia beccifera (L.) Tr. et P1. Las formas de tectigera (también elevata) varían sobre Vismia, de tal manera que se puede juzgar este tipo de dibujo sólo como tipo promedio. (Fig. 5 en Vismia beccifera (L.) Tr. et P1., de los Llanos orientales, Acacías).

b) Sobre Banara mollis Tul., Flacourtiácea del mismo orden de Vismia (Parientales), se encuentra la forma agudizada y más triangular (Fig. 6). En Banara mollis Tul. de los Llanos orientales, Río Guamal, 450 metros.

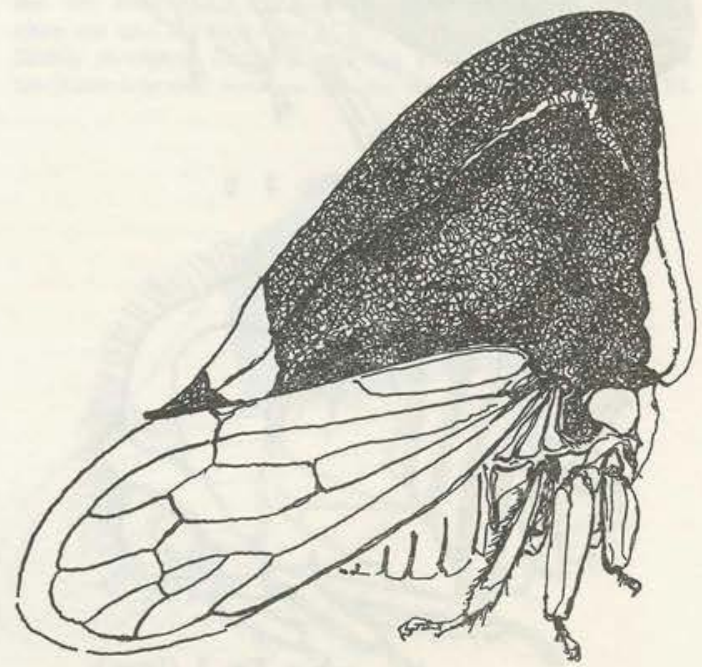

Fig. 6.

c) Sobre Oenotheracea y Melastomatacea viven formas cuyo apéndice pronotal tiene un desarrollo trapezoide. Oenotheracea (Jusiaea sp.) que se encuentra en mayores alturas $(1.300 \mathrm{~m}$.$) , y en Melastomatacea, en 400$ 500 metros sobre el nivel del mar. (Véase Fig. 7: a) tectisera, en Jusiaea sp. de la Cordillera Oriental, río Manzanares-Guayuriba, 1.350 metros; b) elevata, del mismo sitio $\mathrm{y}$ en las mismas planta $\mathrm{y}$ altura).

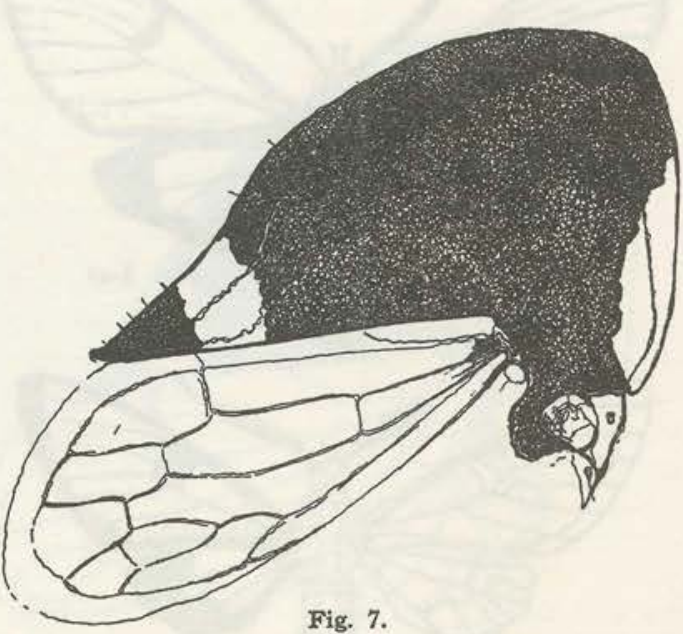

La carina media es de regular anchura. Su límite con el propio cuerpo ("tridimensional") del apéndice pronotal corre en una línea de demarcación 
casi paralela con el margen exterior de la misma carina. Esta línea basal de la carina media es encorvada en el metopidio y en la parte subapical.

El apéndice pronotal y la carina media se prolongan sobre la base de la cabeza. Generalmente esta prolongación no va más allá de la sutura cefálica, pero no son raros, tampoco, los ejemplares en los cuales sobresale y otros que no les alcanza (obsérvense las distintas figuras de tectigera $\mathrm{y}$ de elevata).

Color y dibujo: el apéndice pronotal casi siempre parece negro, pero es solamente de un color pardo (chocolate), más o menos intensivo. El grado de tal densidad está aparentemente influído por la nutrición (3).

(3) Sobre Solanum jubatum Willd. (Caño Grande, Meta, $450 \mathrm{~m}$. sobre el nivel del mar) vive una variedad muy típica de $M$. tectigera. (Fig. 8). En ella la franja frontal ya no tiene línea de demarcación en dirección apical, porque el color general del apéndice (generalmente pardo oscuro) es tan claro que no se distingue de la franja frontal blanca. Solamente poco antes de la franja subapical el colorido blanco-amarillento se pone más y más pardo, pero nunca muy oscuro (hecho que demuestra, difícil de probar en las especies oscuras, que en general la densidad del pigmento se aumenta hacia el ápice, o que la parte anterior del apéndice no tiene más material que la parte posterior).

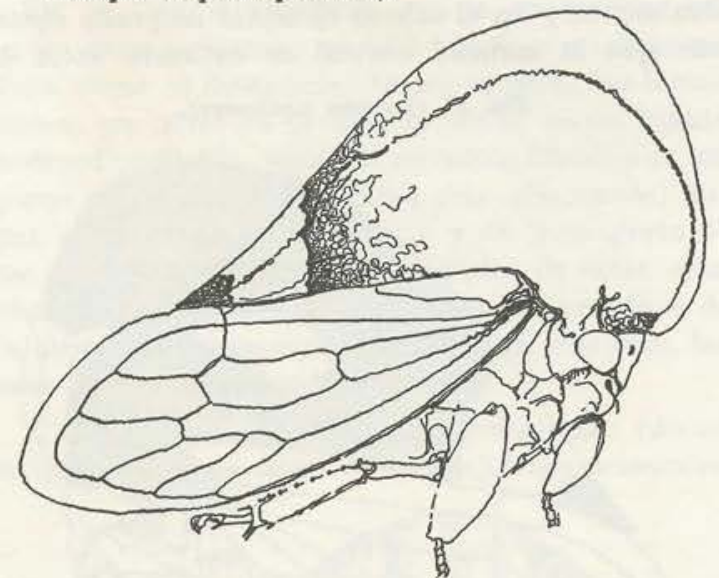

Fig. 8.

De esta especie no se encuentra sino la primera forma, pero de modo muy constante.

A este hecho corresponde completamente la planta huésped y la manera de encontrarse siempre fuera de la selva, pero cerca a su orilla. Si la planta crece a mayor distancia de las selvas, o sea en ambiente más seco, falta inmediatamente esta variedad de tectigera. Aunque frecuentemente se halla esta planta en el valle del Magdalena y sus valles adyacentes, no se ha encontrado nunca tectigera de esta u otra forma. Las larvas no se distinguen de otras de la especie tectigera.

Siempre existe una franja subapical que deja libre un triángulo de cierto tamaño en el color básico como ápice del apéndice pronotal, y una franja frontal, la que sólo se eleva hasta la media altura del margen frontal.

Esta franja blanca frontal puede definirse como el distintivo más simple y más seguro de la especie en cuestion (4).

(4) La franja frontal nunca varía en los ejemplares de una misma cría ni aún en sus más pequeños detalles. Experimentos diversos han confirmado siempre to antedicho; por eso ha side posible reunir los individuos de una misma cría según las formas en detalle de su franja frontal, escogiéndolos de los diversos ejemplares que viven a veces en gran cantidad sobre una misma planta (Vismia, a veces árbol de 6 a 8 metros de altura). Pero cualquiera que sea el aspecto en la variedad de los adultos, las larvas no se distinguen: tienen las espinas dorsales cortas, cónicas y de un color amarillo claro.

Primera forma de Membracis tectigera. M. tectigera Stoll. $\hat{\jmath}$. (Fig. 9). Llanos orientales; vive sobre Vismia beccifera (L.) Tr. et Pl. con apéndice mal desarrollado por la sequedad del aire. Color básico: pardo de densidad variada; franja frontal semialta; franja subapical blanca; el tamaño del apéndice pronotal varía (5).

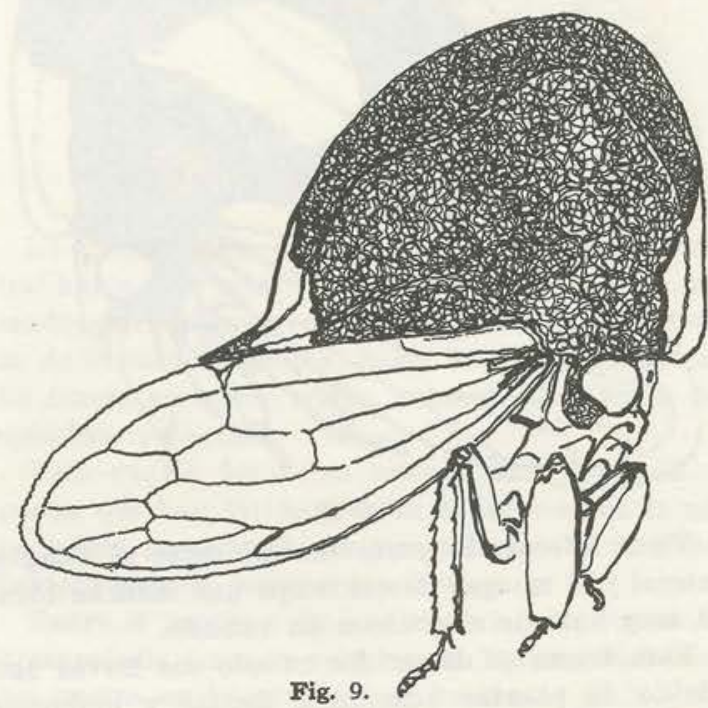

(5) E1 apéndice pronotal varía en su tamaño independientemente del tamaño del cuerpo, inclusive las tégmina. Ejemplares de igual tamaño de cuerpo pueden llevar su apéndice pronotal de un largo y una altura muy distintos.

Por consiguiente, parece de poco valor taxonómico la comparación entre el largo del apéndice pronotal y el largo de las tégmina.

$\mathrm{La}$ causa de estas diferencias es la sequedad del ambiente después de la última muda, lo que sucede muchas veces; por eso la influencia de la temperatura origina consecuencias absolutamente mecánicas (Fig. 9).

Generalmente se encuentra esta primera forma solamente en ejemplares que en su estado de larva vivían fuera del bosque en Vismia beccifera (L.) Tr. el Pl.; en la selva sólo si trataba de ejemplares de un desarrollo larval algo débil (6).

(6) Las larvas están adheridas sin moverse a lo largo de la nervadura principal en el envés de las hojas. Cuando aparece el adulto, se ve siempre que los ejemplares más desarrollados son los que se han alimentado cerca a la raíz de la hoja, y que los que se alimentan cerca del extremo final de la hoja son tanto más débiles y sencillos en su dibujo, aun cuando las larvas pertenezcan a una misma cría. La influencia sobre la hoja, donde las larvas están chupando, se manifiesta de inmediato, cuando una larva hunde su trompa en la nervadura lateral de la hoja, pues la zona respectiva de la hoja alimentada por esta nervadura se seca dentro de poco tiempo. De este hecho se puede deducir que la colocación de las larvas, una detrás de la otra, sobre el mismo nervio de la hoja hace llegar tanto menos alimento a la segunda o tercera de la fila, por lo cual no llegarán sino a un desarrollo pobre.

$\mathrm{Y}$ no es raro observar que sobre un solo nervio más de diez larvas están buscando su alimentación; esas larvas no cambian de lugar sino apenas por una perturbación externa, lo que prueba fácilmente el hecho 
de que muchas veces queda pegada una muda con la otra, es decir, que ni siquiera cambian esos animales de lugar durante la muda.

Segunda forma de Membracis tectigera (lefevrei Buckton). - Fig. 10. Hembra, macho y larva; río Tacana (Amazonas), en el margen de la selva, sobre Melastomatácea sp.; obsérvese el movimiento de la mancha central hacia la franja frontal).

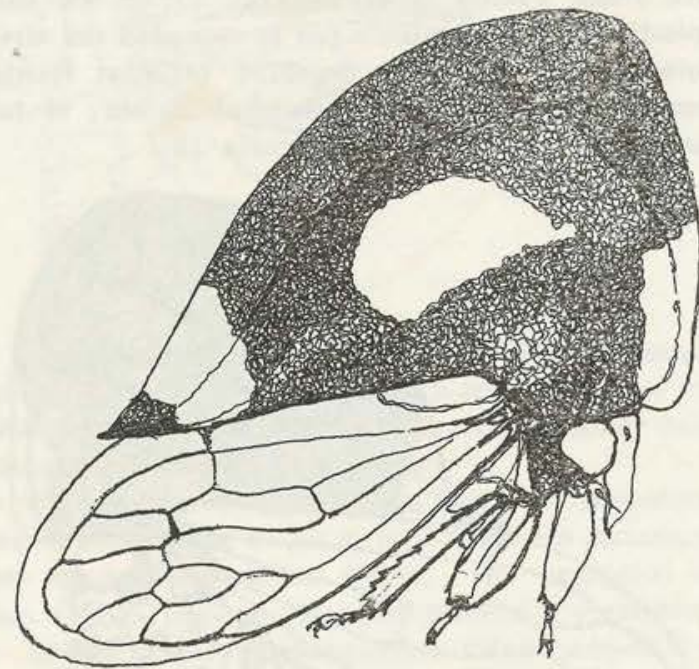

Fig. 10.

Vista lateral: la parte central entre el margen lateral y el margen dorsal ocupa una mancha blanca muy variada respecto a su tamaño.

Esta forma se desarrolla cuando sus larvas han vivido de plantas huéspedes, densas y umbrosas (Vismia angusta Miq.) o de plantas que se hallan al borde de las selvas (Tococa guyanensis Aublet).

Sobre estas plantas y en este ambiente se desarrollan muchas veces las dos primeras formas de tectigera, y sus cantidades respectivas resultan de la proporción entre los rayos solares y la sombra, es decir, según los factores que determinan una graduación en la humedad. Tales observaciones han dado iguales resultados en los Llanos orientales, en el valle del Magdalena y en la región amazónica.

Tercera forma de Membracis tectigera (confusa Fairmaire). - Fig. 11. \& De los Llanos orientales, río Guayuriba, vive sobre Miconia serrulata Naud., en la selva, 470 metros.

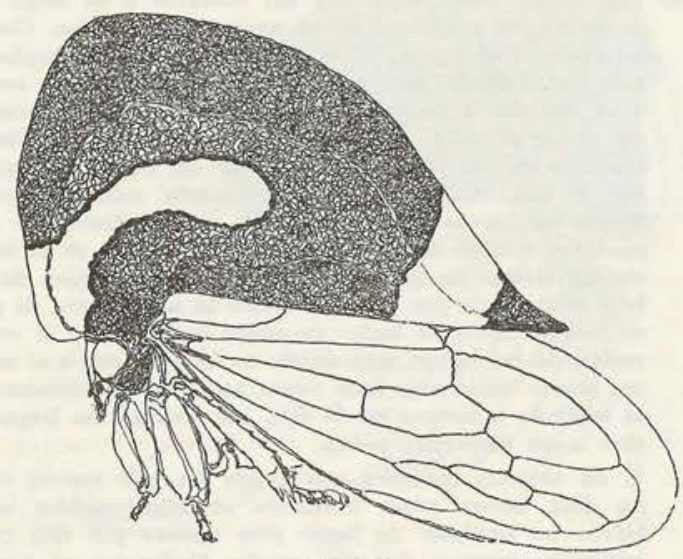

Fig. 11.
Fig. 12. , río Tacana, Amazonas, en la selva sobre Inga sp., 180 metros.

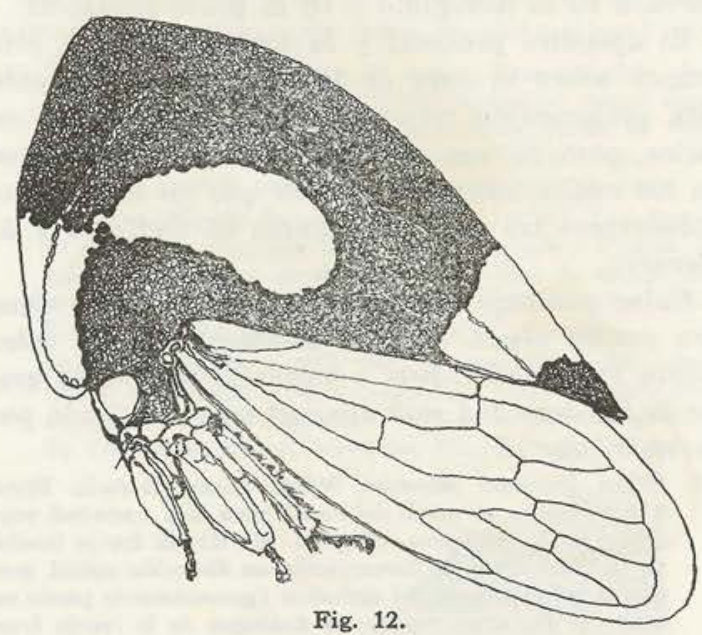

Fig. 13. ㅇ, río Carare, en la selva sobre Melastomatácea sp., 320 metros.

Vista lateral: sobre los humerales se encorva en cada lado una franja que une la mancha central con la franja frontal. Esta unión se desarrolla gradualmente, y en el mismo ejemplar se puede observar que la mancha central se extiende hacia la

Fig. 13 (las tres siguientes).

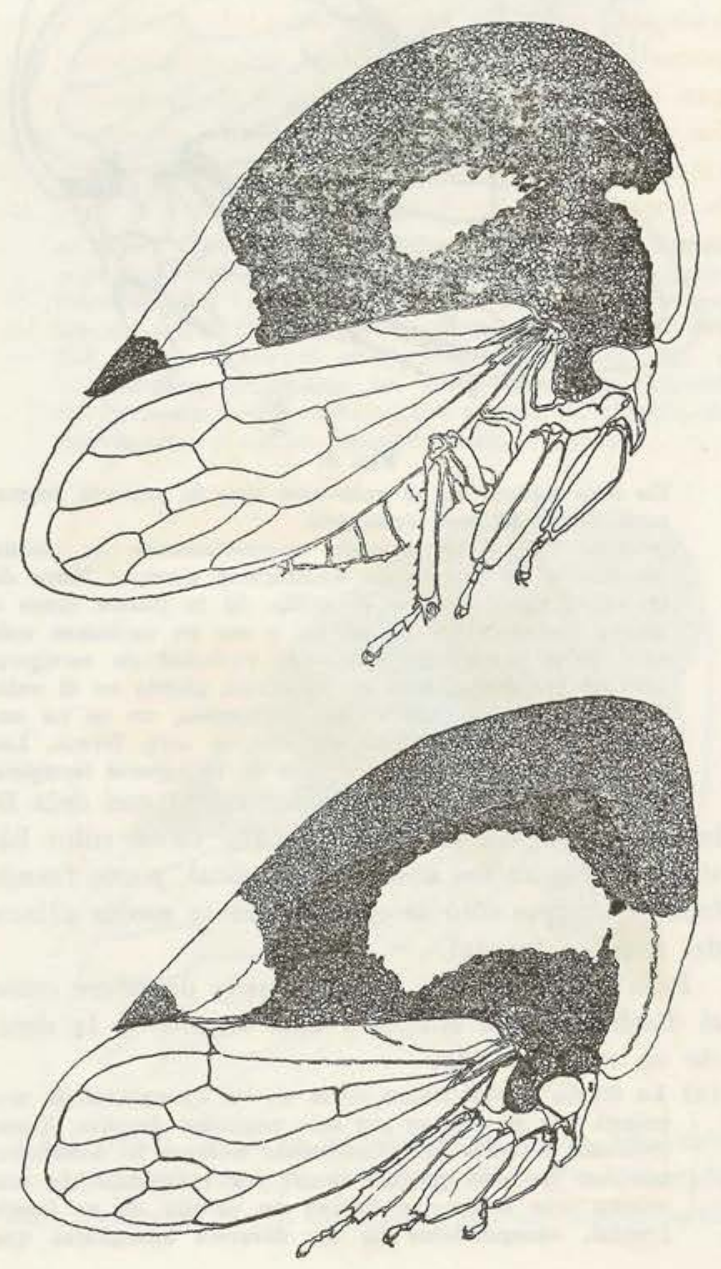




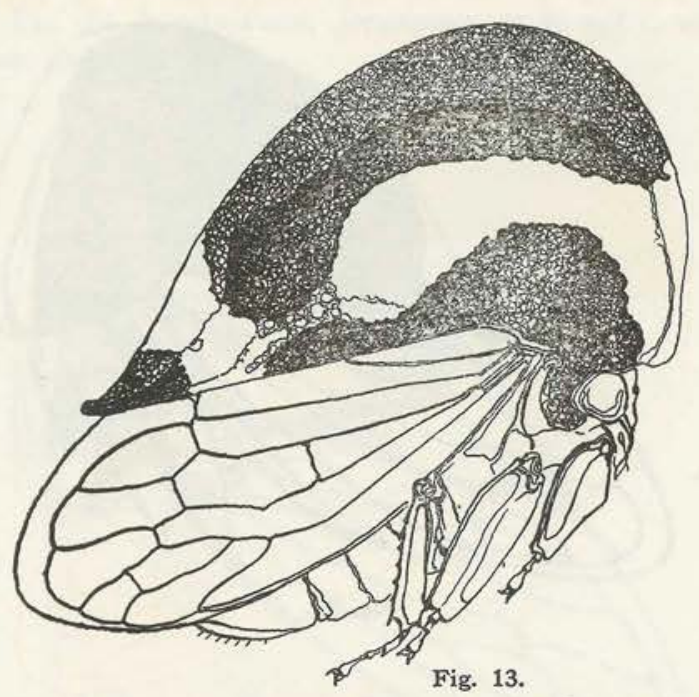

franja frontal y de ésta hacia la mancha central. De la intensidad de ciertos factores en el ambiente respectivo depende que su influencia logre la formación más o menos desarrollada de la franja horizontal ya mencionada.

En la especie tectigera, nunca se realiza una unión entre la mancha central y la franja subapical. Para llegar al desarrollo (forma tercera) las larvas tienen que vivir en el interior de la selva. Planta huésped preferida: Miconia serrulata Naud. Aún así pocos individuos de la misma cría (hermanos) llegan a ese grado de desarrollo, y en la mayoría de los casos - conforme al modo típico de estar estacionados uno detrás de otro sobre la nervadura de la hoja- se encuentran también, una tras otra, las tres formas mencionadas.

Cuarta forma de Membracis tectigera: (dorsata Fairmaire). - Figs. 13 y 14. Llanos orientales,

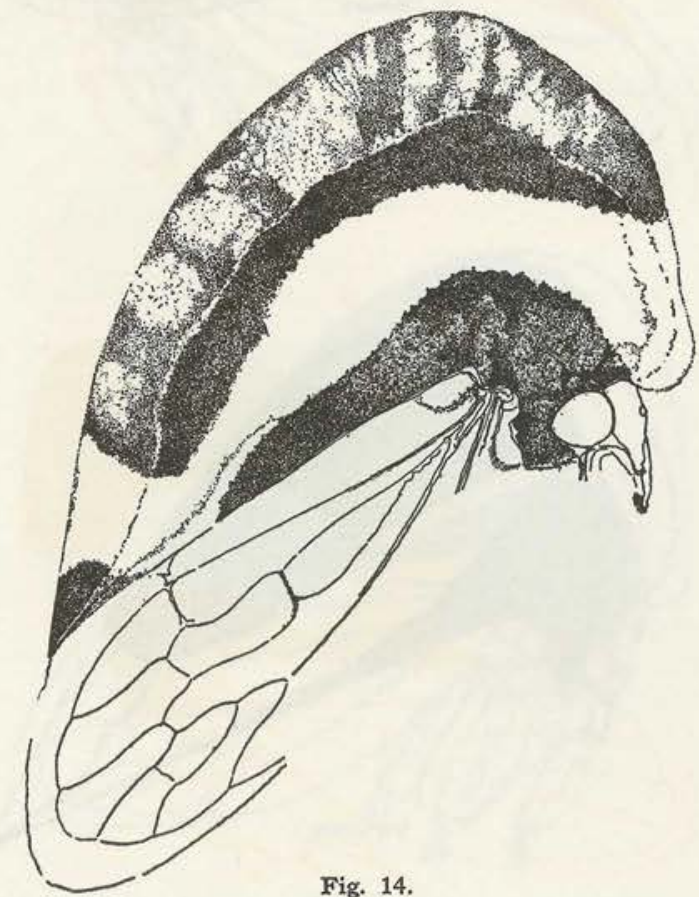

450 metros; sobre Piper, en la selva del Caño Grande.

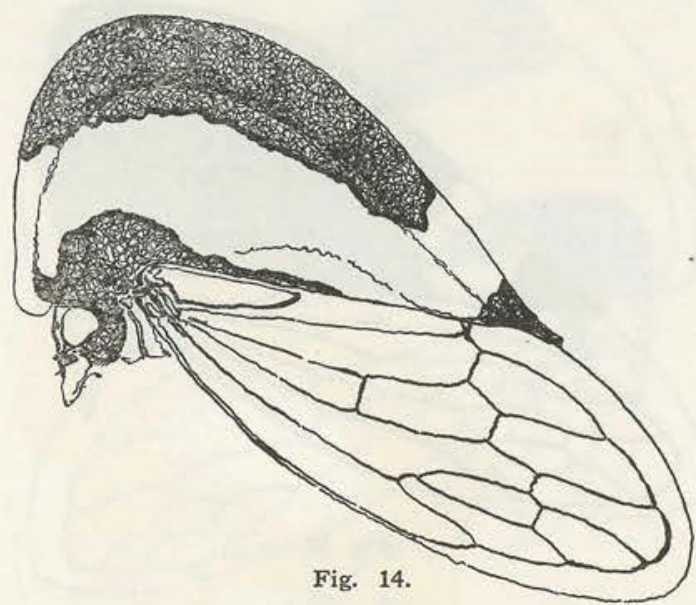

La franja blanca lateral corre de la mancha central hasta la frontal (igual a la forma tercera), pasando sobre los humerales, pero, además, se extiende de la mancha central hasta la franja subapical. La franja subapical nunca cubre todo el ápice del apéndice pronotal.

Esta cuarta forma es consecuencia de aquellas larvas que han vivido sólo en el interior de la se] va $\mathrm{y}$ que se alimentaron exclusivamente de Piper fusagasuganum quenanense Trel.

Entre el macho y la hembra ésta siempre se ha desarrollado como la más fuerte. Por eso de la forma cuarta no se pudo ver un macho.

\section{MEMBRACIS ELEVATA Fabricius.}

Fig. 15. Río Carare, 300 metros de altura; en rastrojo sobre compuesta.

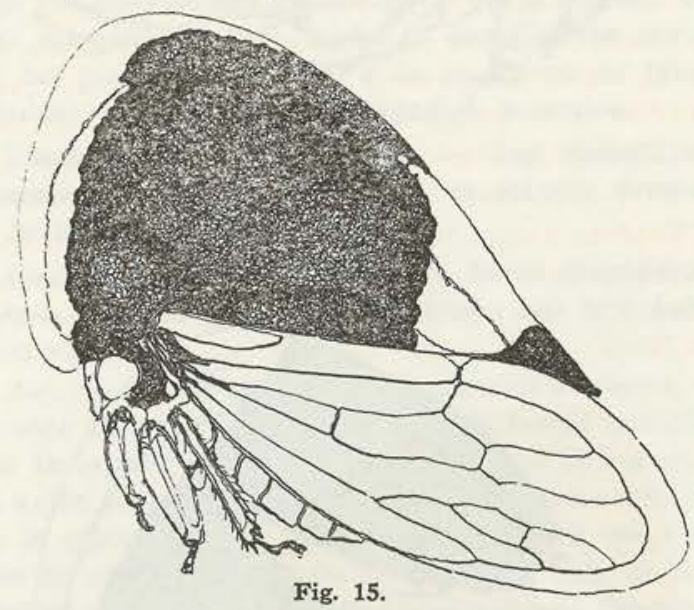

Fig. 16. Llanos orientales, Villavicencio, $490 \mathrm{me}$ tros de altura; margen de la carretera, sobre Vismia beccifera.

Fig. 17. Leticia, Amazonas, trocha hacia la selva, sobre Vismia.

Fig. 18. Caño Grande, 450 metros de altura ; margen de la selva, sobre Vismia $s p$.

Fig. 19. Villavicencio, en la selva, 640 metros de altura; sobre Piper. 


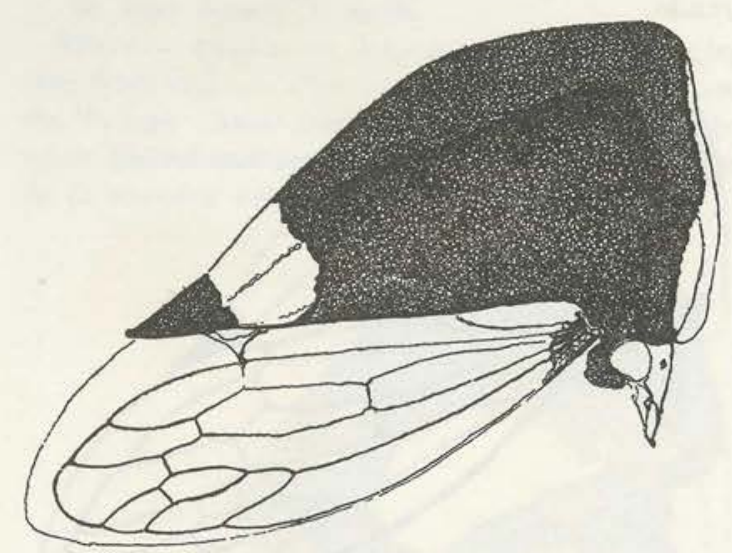

Fig. 16.
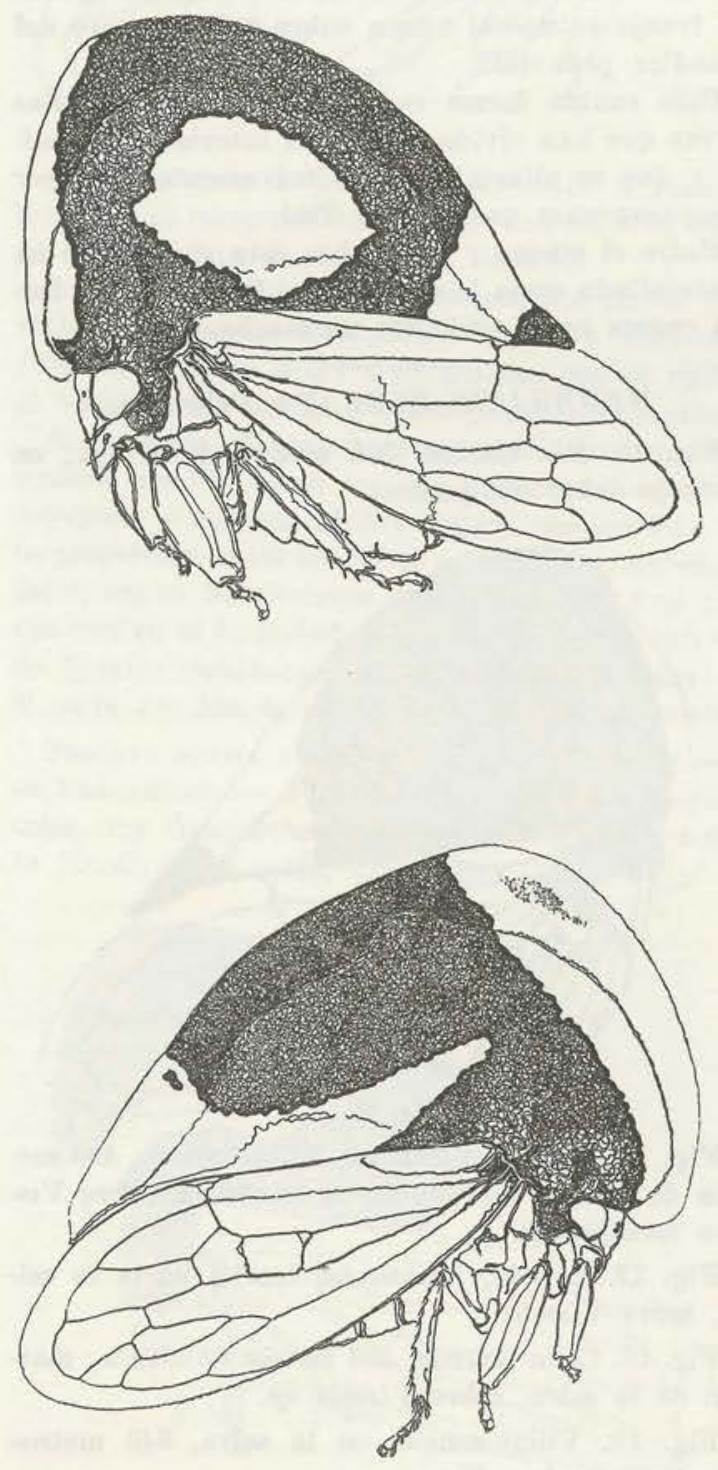

Fig. 19.

Fig. 18.

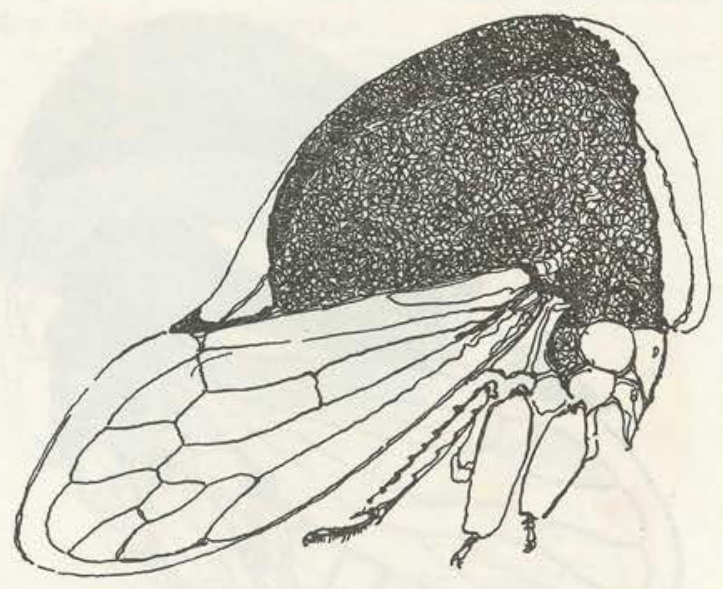

Fig. 17.
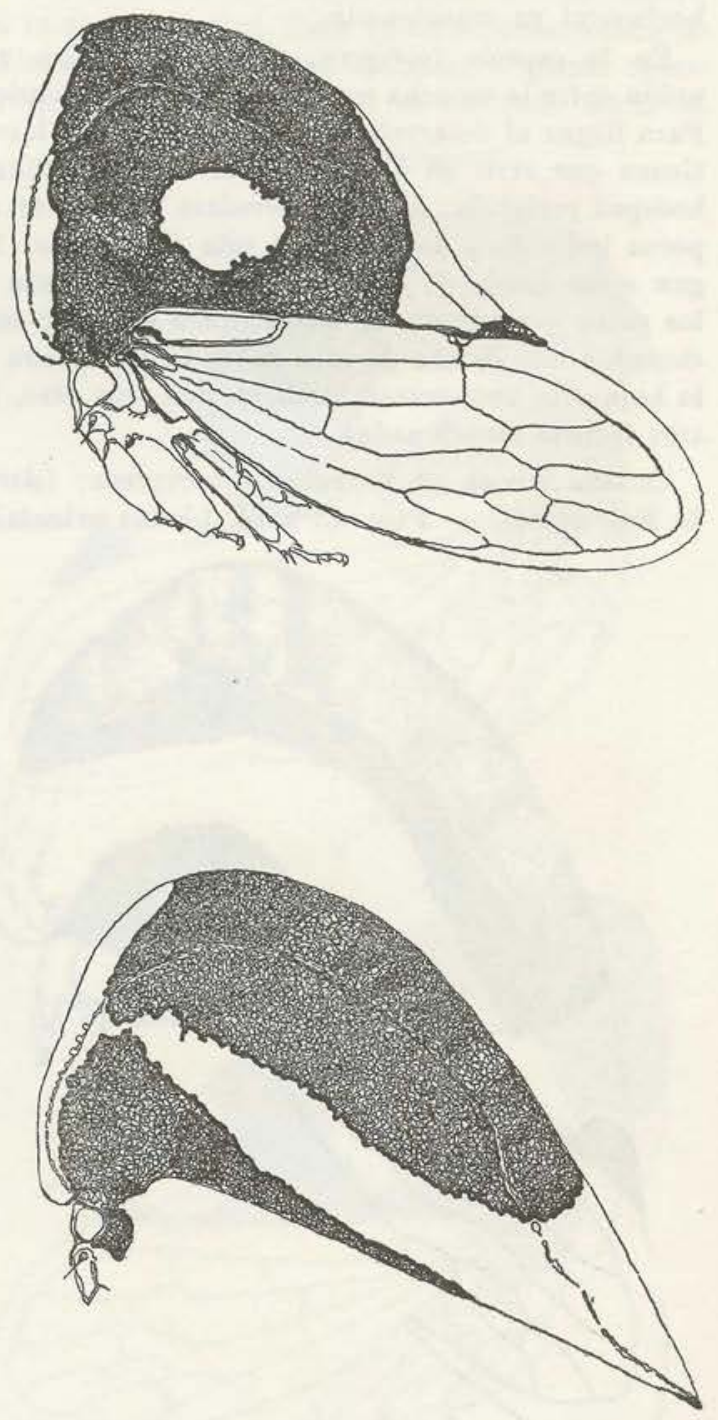
Fig. 20. Loreto-Yacu, Amazonas, en la selva, sobre Leguminosa.

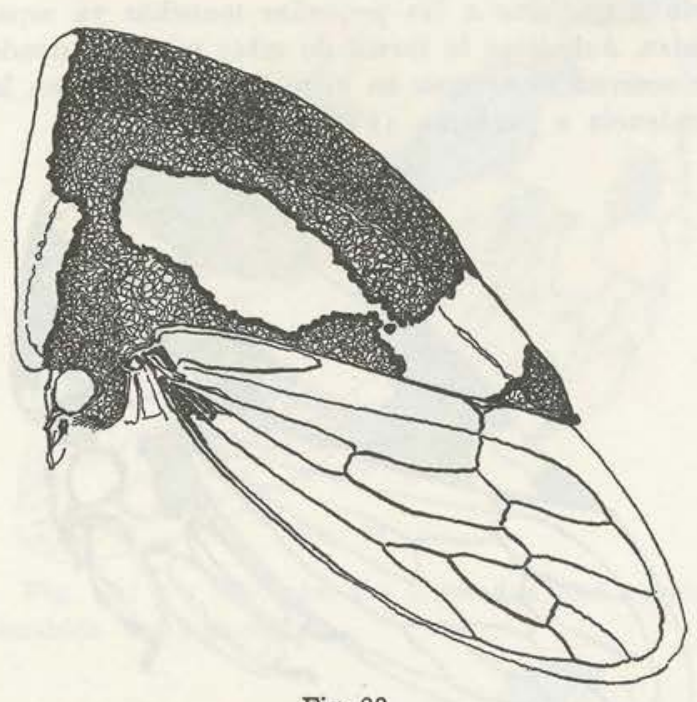

Fig. 20.

Figuras 21. Todas de los Llanos orientales, en las selvas, al pie de la cordillera, sin excepción en Piper fusagasuganum-quenanense Trel. Altura sobre el nivel del mar: 500 metros.

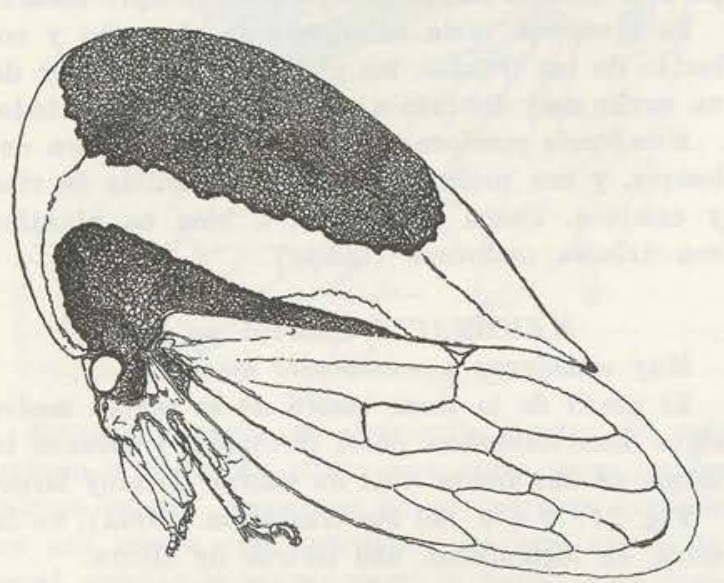

Fig. 21 .

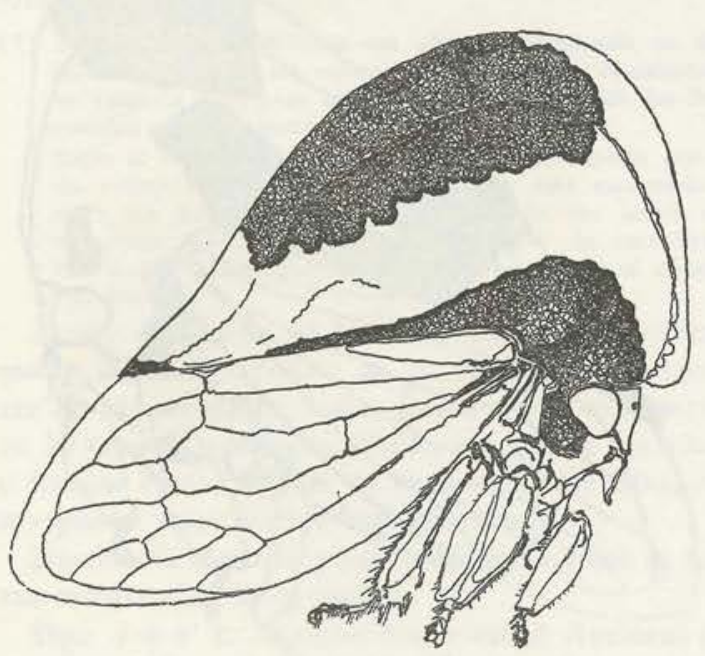

Fig. 21.

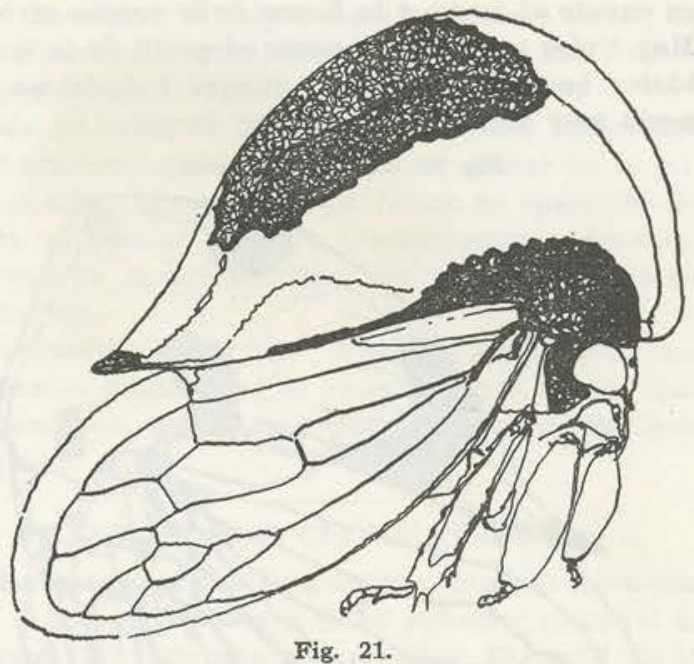

Las características para todas las formas de esta especie son las siguientes: El margen frontal del apéndice pronotal con franja blanca en toda su altura.

La larva tiene espinas dorsales delgadas, largas y de color negro.

Esta especie también ha desarrollado cuatro formas. La escasez de ciertas formas, en regiones muy selváticas (Opón y Carare) resulta aparentemente de la completa falta de ambiente favorable (terreno abierto).

Primera forma de nlevata. - Los ejemplares, por ser mal nutridos en su estado larvario, o los que viven en condiciones de aire seco, resultan sin manchas laterales.

Segunda forma de mlevata. - Según la humedad del aire dentro del bosque y de la sombra de sus márgenes, o bien según la cantidad de savia de las plantas huéspedes, o de la especie de tales plantas, esta forma tiene manchas laterales.

Tercera forma de mlevata. - Los ejemplares muestran franja de unión entre la mancha lateral y la franja subapical.

Cuarta forma de elevata. - Estos ejemplares tienen, además, una franja de unión con la franja frontal.

Así, se distinguen, pues, las especies tectígera y elevata de modo fundamental, por la forma tercera. En la especie tectigera no existen individuos con la unión entre la franja apical y la mancha central; en la especie elevata faltan los individuos que tienen la unión entre la franja frontal y la mancha central, forma ésta que se encuentra con frecuencia en la especie tectigera.

\section{MEMBRACIS MEXICANA Guer.}

Esta especie tiene también una franja frontal semialta, la que se une a una mancha central-lateral; pero de esta última corre una franja al dorso, mientras que una unión con la franja subapical no se realiza nunca. La línea básica de la carina media es muy constante en su forma, y lo mismo se nota 
en cuanto al ancho y la forma de la propia carina. Muy típico es que se empunta el perfil de la línea básica hacia el metopidio, aunque todavía no de modo muy marcado (no es muy largo).

Fig. 22 (las tres siguientes).
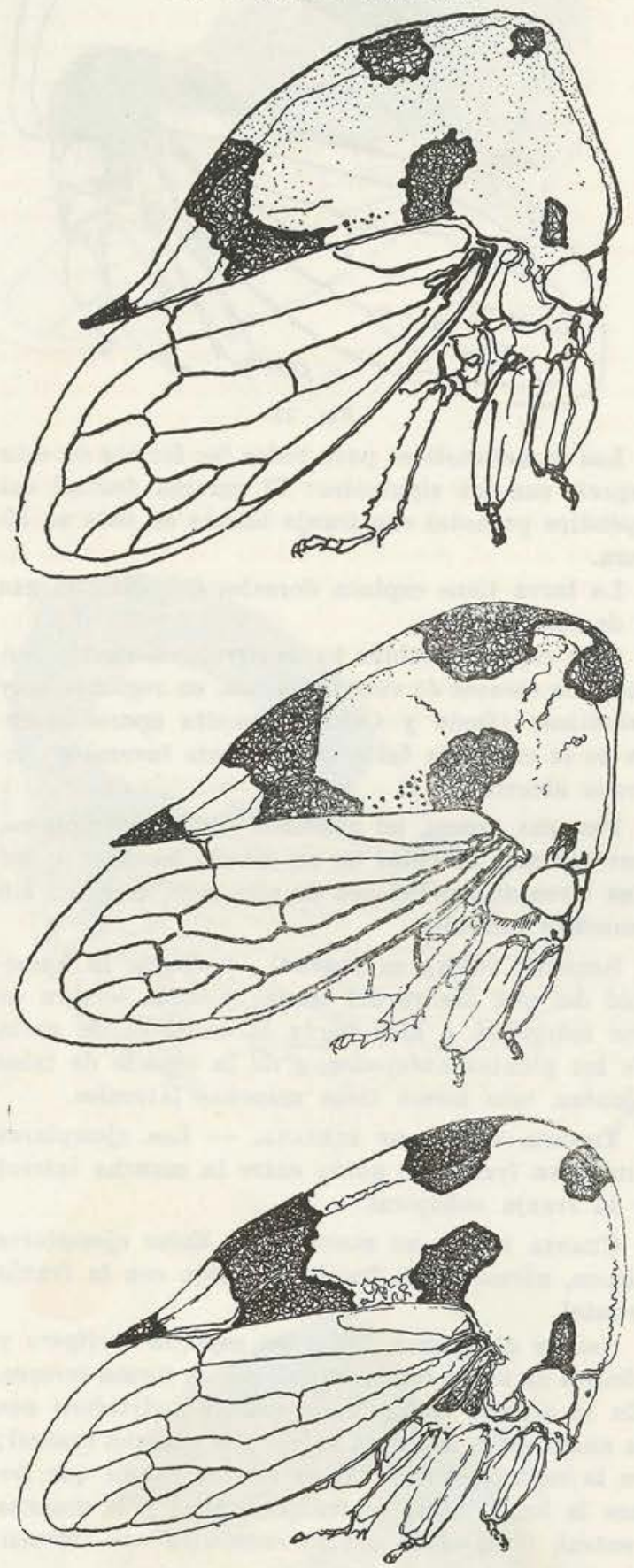

La mancha oscura en el metopidio, que resulta por la unión de la franja frontal con el dorso, tiene generalmente interrupciones, más o menos anchas (Fig. 22, dos tipos de mexicana con la mancha en el metopidio dividido y con la misma mancha entera. Río Ocoa, Llanos orientales, sobre Vismia beccifera en llano abierto (borde del camino), 430 metros.

Fig. 23. La misma especie mexicana, de Queta- me (Cundinamarea), 1.700 metros, en cafetal, pero queda negra la fila del borde dorsal como ultimo relicto que une a las pequeñas manchas ya separadas. Asimismo la forma de estas manchas donde se acercan al margen en el metopidio muestran la tendencia a juntarse. (Fig. 23).

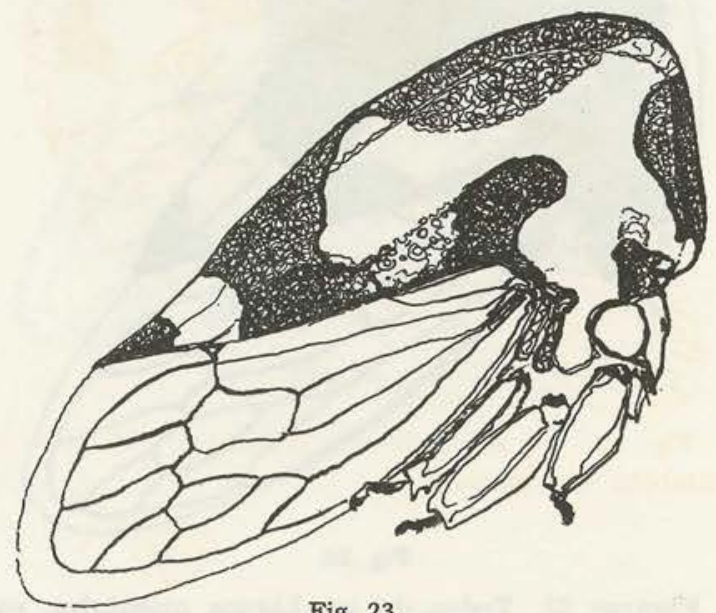

Fig. 23.

El color de la franja frontal $y$ el de todas las demás franjas de unión es siempre amarillo (amarillo claro hasta anaranjado-oscuro y amarillopardo). Sólo la franja subapical es siempre blanca.

Esta especie varía solamente en el ancho y colorido de las franjas, las cuales ya pueden ser de un ancho muy distinto o ya pueden faltar del todo.

Membracis mexicana sólo se encuentra fuera del bosque, y con preferencia sobre las orillas de ríos y caminos, llenas de maleza, o bien en plantíos con árboles umbrosos (cafeto).

\section{MEMBRACIS FLAVA sp. n.}

Muy semejante a membracis mexicana.

El perfil de la línea básica de la carina media sigue desarrollándose en el metopidio y alcanza la forma de una punta o de un cuerno no muy largo.

Fig. 24: $\hat{o}+$ + del río Guatiquía (Meta), en la selva, en leguminosa, 430 metros de altura.

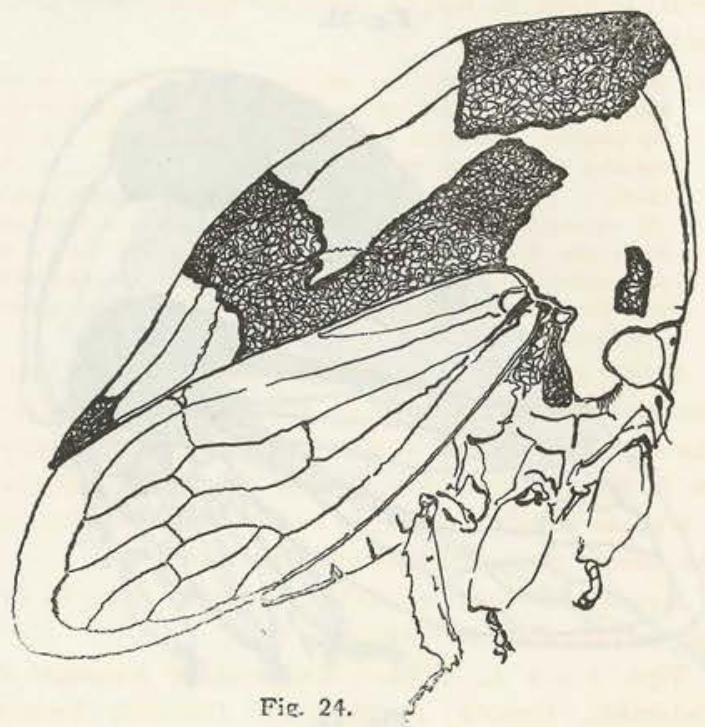




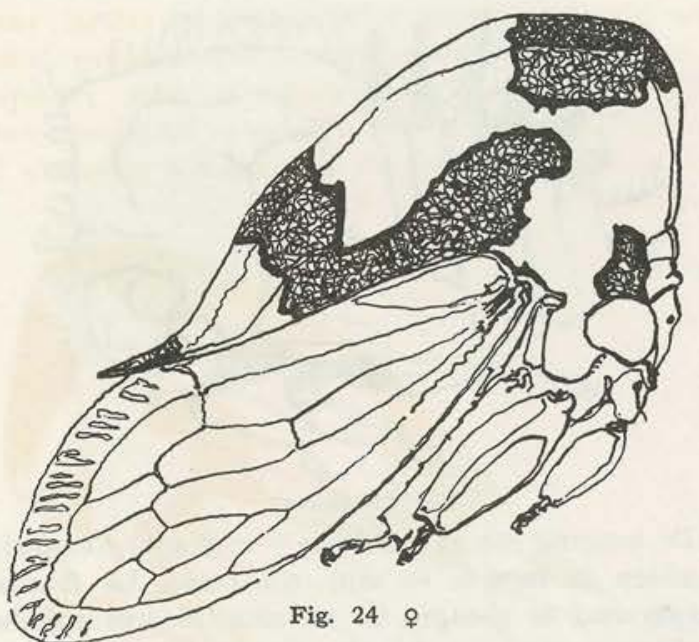

Fig. 25: $\subsetneq$; selva del río Humadea, 400 metros, también en leguminosa.

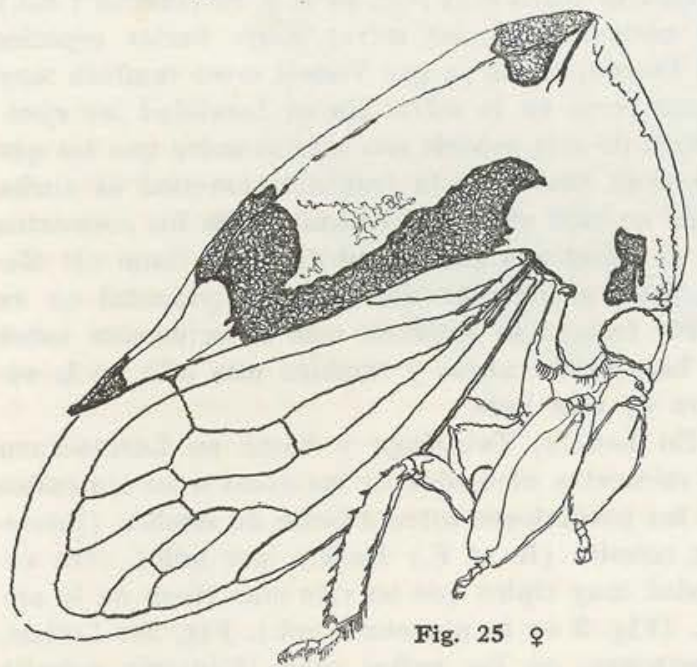

Simultáneamente se desarrolla dentro de este cuerno y desde su punta una corta pero precisa carina lateral. Asimismo se encontraron también en una misma cría individuos sin esta carina lateral, aunque la mayor parte la tenían bien desarrollada (7).

(7) Según las características del género Membracis no debiera encontrarse tal carina lateral, pero de encontrarse no importa que pase solamente por encima de los humerales o que apenas los alcance.

Dado el hecho de que si se encuentra la especie con o sin carina lateral, se habrá de añadir esta característica a las del género Membracis y a la vez habrá de enmendar, por una definición respectiva, la característica de la carina lateral, en lo que se refiere al género Phyllotropis.

A este desarrollo de la línea básica de la carina media sigue una fusión de las dos manchas oscuras en el metopidio, fusión que a veces se observa en la especie mexicana. Todas las demás manchas o franjas varían dentro de características fijas, como puede verse en las reproducciones.

Membracis flava se puede considerar como la forma selvática de la mexicana.

Tipo $\delta+q$ L. Richter. Universidad Nacional de Colombia, Bogotá. Instituto de Ciencias Natura- les. Localidad del tipo: río Guatiquía (Meta), en la selva; 450 metros sobre el nivel del mar; sobre Leguminosa; mayo 25 de 1945.

En relación con la limitación de las influencias del ambiente (viviendo solamente dentro de la selva $y$ sobre leguminosas) la forma de aparición de esta especie se muestra esencialmente constante, lo que ya se demostró por las mismas razones en mexicana.

Desarrollo observado: franja frontal corta con conexión transversal al centro dorsal, franja que lógicamente sigue desarrollándose en la siguiente especie.

\section{MEMBRACIS CINGULATA Germ.}

La carina media se ensancha considerablemente en el metopidio, lo que da al apéndice pronotal la forma típica de una media elipse. El perfil de la línea basal de la carina media tiene la forma de un cuerno todavía más considerablemente prolongado, y como consecuencia se prolonga también la carina lateral, pero sin alcanzar las humerales. No se encontraron ejemplares sin esta carina lateral $\left(^{*}\right)$. Fuera del colorido, dicho cuerno es la unica característica que varía en esta especie.

La carina lateral llega al margen externo muchas veces, lo mismo que queda con igual frecuencia alejada de éste.

Variaciones típicas se observan, cuando esta especie vive sobre plantas huéspedes distintas.

La especie cingulata es muy común en los Llanos hasta el Amazonas, pero no se encuentra en el valle del Magdalena; no vive sino en el interior de las selvas sobre una especie de Cecropia y es tan frecuente que es imposible encontrar una de estas plantas sin una docena de cingulata (Fig. 26. Caño Grande, Meta, 480 metros de altura, en la

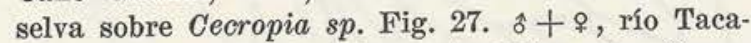
na, Amazonas, en la selva y también sobre Cecropia $s p$.)

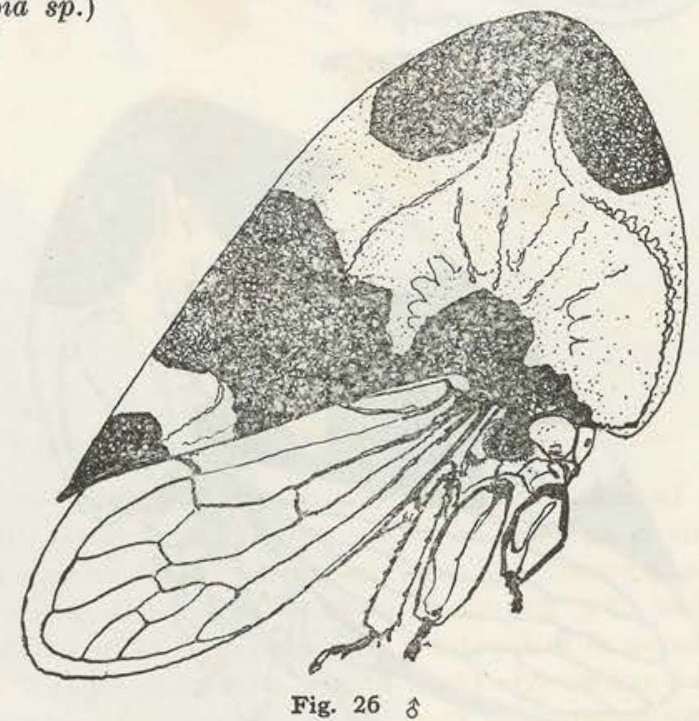

(*) En el valle del Magdalena se eneontró la especie sin carina lateral cuando este trabajo estaba en la imprenta. En un estudio posterior será descrita esta interesante especie. 

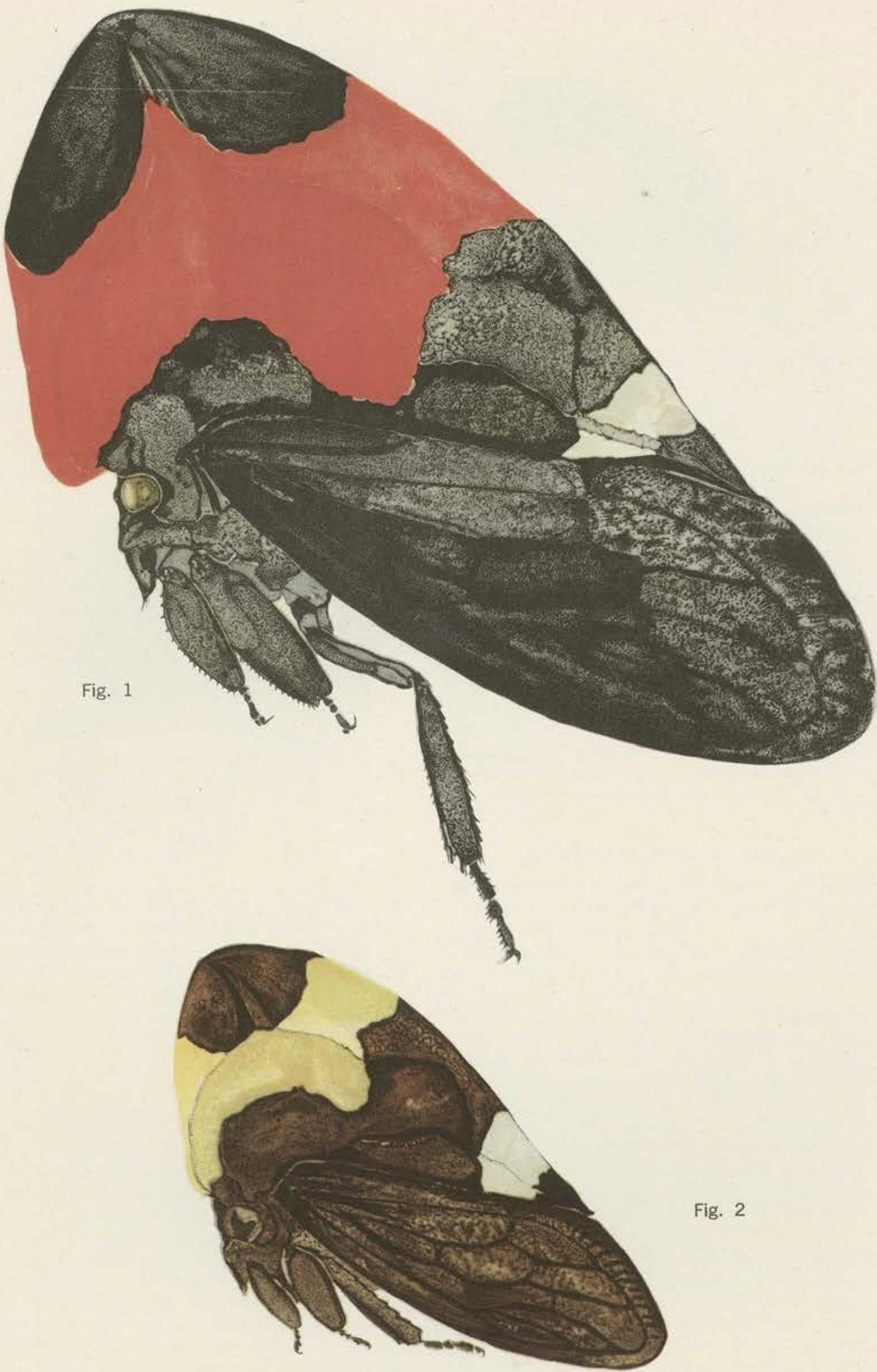

Fig. 2

Fig. 1. - Membracis cingulata Germ.

(Variedad. muy rara, dei Amazonas y Llanos del Meta).

Fig. 2. - Membracis cingulata Germ.

(Variedad típica de las regiones de Leticia, Tabatinga y Loreto-Yacu, Amazonas).

(Dib. L. Richter) 


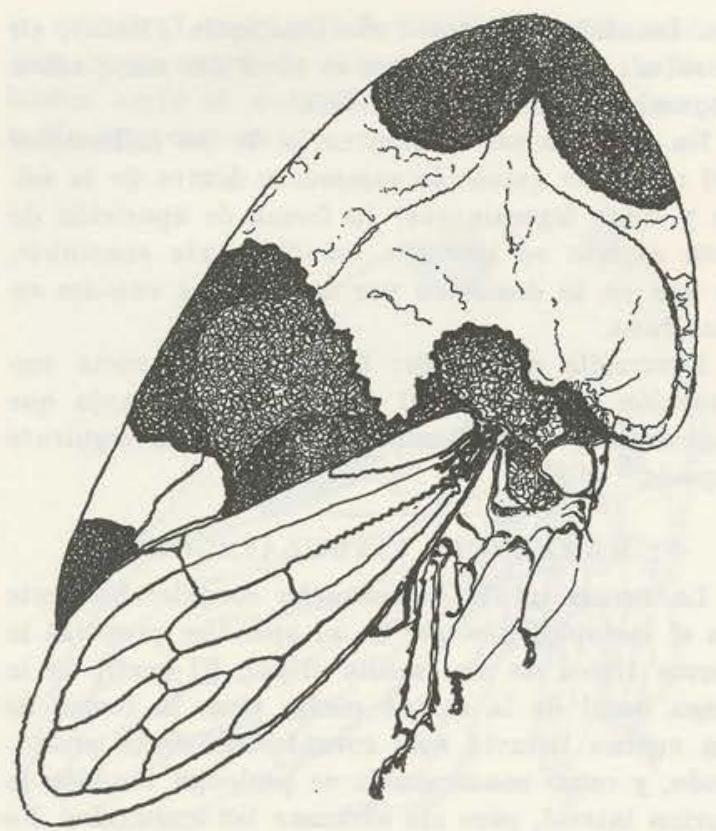

Fig. 26 우

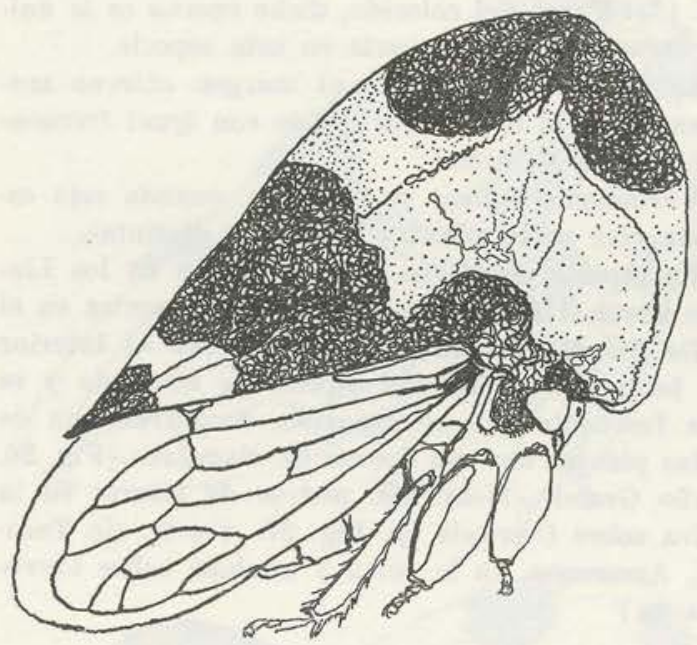

Fig. 26.

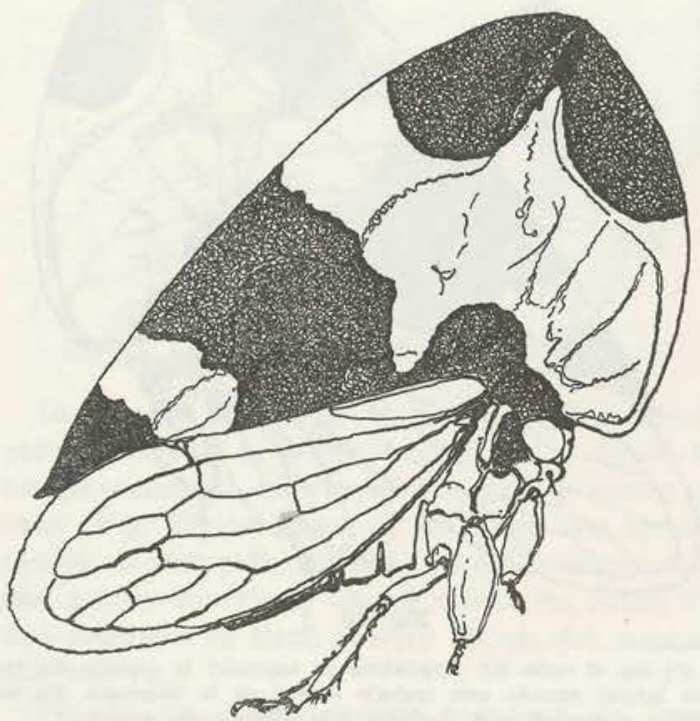

Fig. 27.

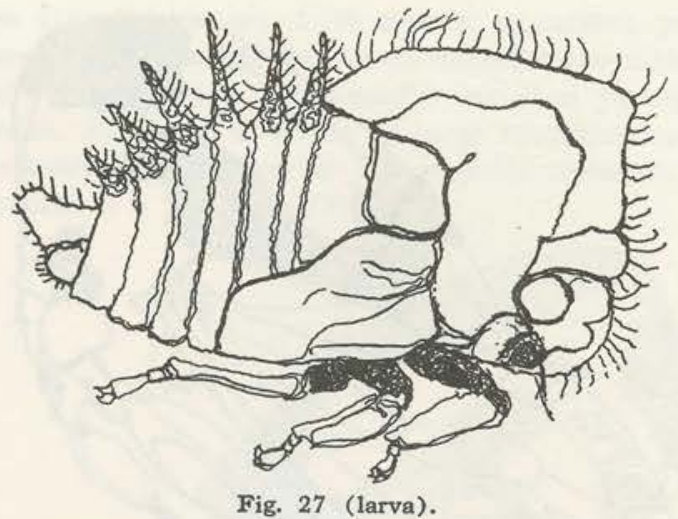

De acuerdo con el ambiente y la planta huésped, también la especie es muy constante. La franja transversal es siempre de un amarillo anaranjado y de un ancho regular. Los machos son siempre más pequeños que las hembras.

Una variedad muy rara (Fig. 1, en plancha I col.) se encuentra en las selvas sobre varias especies de Vismia, raras, ya que Vismia crece también muy raras veces en la selva. En su totalidad los ejemplares de esta especie son más grandes que los que viven en Cecropia; la franja transversal es ancha y de un rojo vivo muy constante. Se les encuentra en el Amazonas como también en el llano del Meta. La prolongación del apéndice pronotal en su parte frontal se extiende más notoriamente sobre la base de la cabeza y también más allá de la sutura de esta base.

En Leticia, Tabatinga $\mathrm{y}$ hasta en Loreto-Yacu se encuentra alrededor de las casas o en las calles de las poblaciones sobre árboles de sombra (Pouteria caimito (R. et P.) Radk.), por miles, otra variedad muy típica que no vive sino fuera de la selva. (Fig. 2 en la plancha I col.). Fig. 28: Leticia, Amazonas, en las calles sobre Pouteria caimito

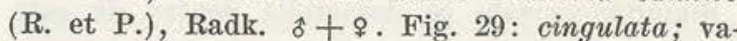
riación sobre Vismia, (v. Pl. I, Fig. 1 en col.); 600 metros en la selva de Caño Grande.

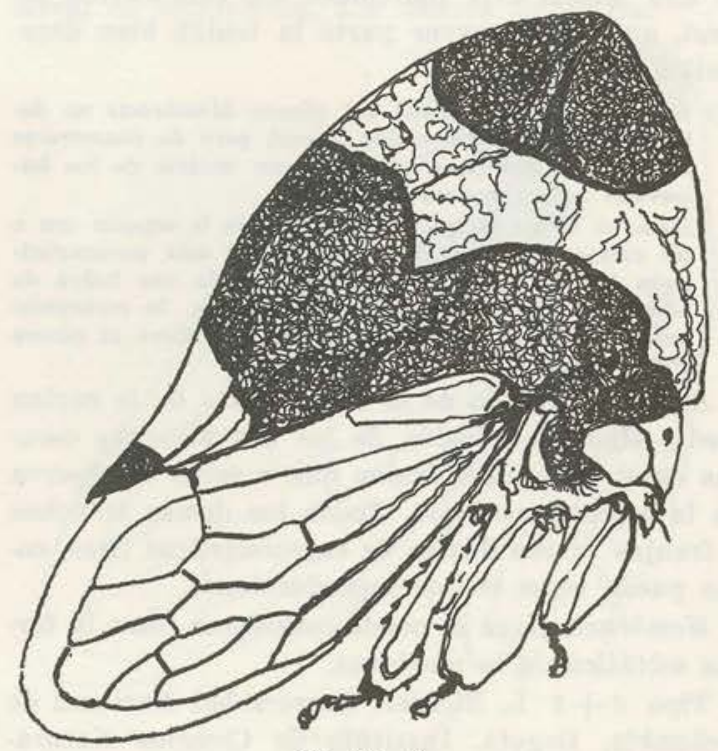

Fig. 28 के 

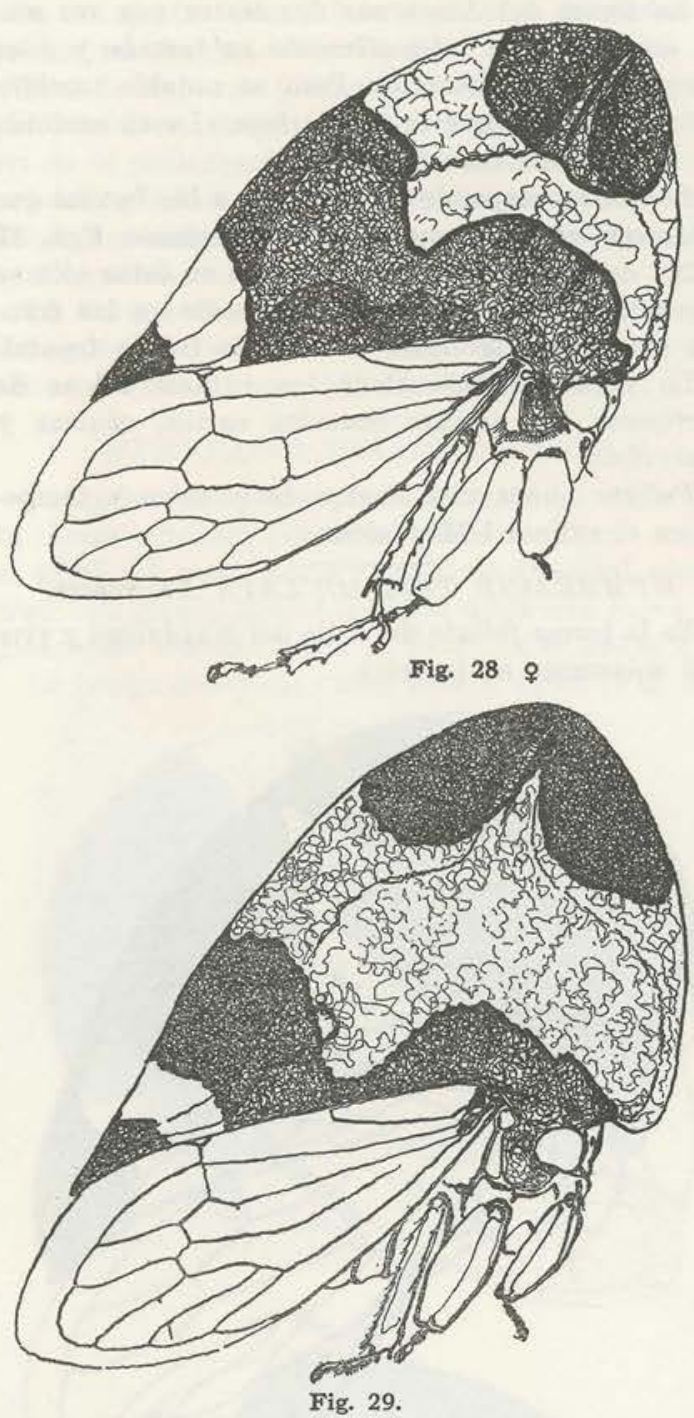

Esta especie es más pequeña (véanse Figs. 28 y 29) ; su franja transversal más angosta y su color amarillo-pálido. Todo su aspecto se asemeja a Membracis nigroluta Funkh. de Minas Geraes, la que aparentemente pertenece a este grupo (8).

(8) Enchophyllum cruentatum Germ. muestra la misma forma con una carina media de la misma forma de la línea basal; es decir, en forma de un cuerno muy prolongado. También en Enchenopa pueden distinguirse formas análogas.

\section{MEMBRACIS TOCOCAAE sp. n.}

Esta especie demuestra todas las características de tectigera con un desarrollo hacia cingulata.

La larva se distingue de la de tectigera solamente por un apéndice pronotal que es un poco más grande en su parte anterior.

Hay una franja transversal en línea recta de la franja frontal semialta hacia el dorso (Fig. 30: $\delta$, en la selva del río Ocoa, Guatiquía, 430 metros de altura, sobre Tococa guyanensis Aublet.).

El centro que es un poco más ancho muestra que originalmente existió una mancha central. La conexión con la franja frontal es también más ancha
Fig. 30.

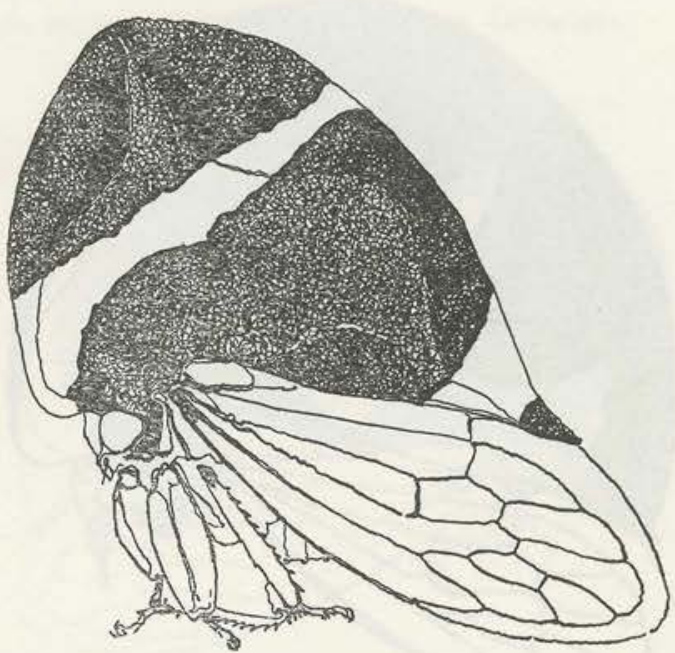

que la efectuada con el dorso, lo que señala el curso típico de la franja como en tectigera.

La línea basal de la carina media en el metopidio tiene la forma de cuerno con una carina lateral incrustada.

El colorido de todas las franjas es blanco.

Se encontró la especie sobre Tococa guyanensis Aublet al borde de un bosque aislado, en los Llanos orientales, cerca de la confluencia de los ríos Ocoa y Guatiquía.

Tipo: macho y larva L. Richter, Universidad Nacional de Colombia, Bogotá. Instituto de Ciencias Naturales.

Localidad del tipo: ríos Ocoa, Guatiquía (Meta), 430 metros de altura sobre el nivel del mar; en la selva sobre Tococa guyanensis Aublet.; 22 de febrero de 1941.

\section{MEMBRACIS FOLIATA Lin.}

Esta especie pertenece a un grupo con hábitus de tectigera, que por primera vez desarrolla la parte apical del apéndice pronotal.

Aparentemente, con este nuevo desarrollo cambian también el dibujo y la posición de las franjas, de modo consecuente.

La franja frontal sale del frente. En ejemplares de los Llanos este hecho se manifiesta solo parcialmente, es decir, una parte sobre la base cefálica queda en contacto con el frente (Fig. 31; Buena Vista, Meta, 1.100 metros sobre el nivel del mar, $\hat{\delta}$, en Isertia haenkeana), mientras que en la región amazónica colombiana se encuentran también ejemplares que tienen esta franja ya completamente separada de las márgenes (Fig. 32: río Amazonas, en rastrojo cerca de Leticia, sobre Vismia sp. ô)

Las manchas centrales y laterales del apéndice pronotal quedan siempre aisladas de la franja frontal. Ejemplares menos desarrollados muestran, además, la mancha central separada de la franja subapical (Fig. 33: Manzanares, Meta, $1.000 \mathrm{me}$ tros sobre el nivel del mar, en Vismia becoifera, terreno abierto ?). 


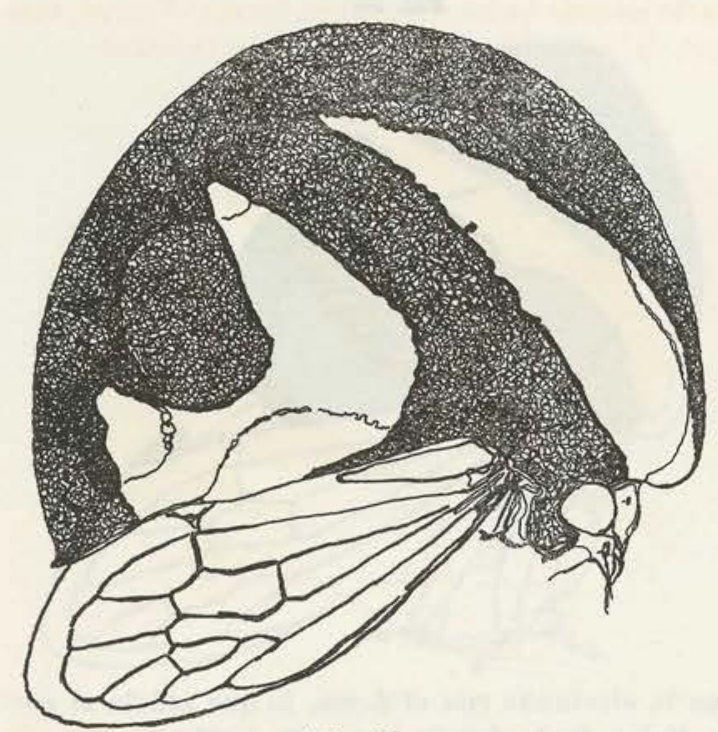

Fig. 31.

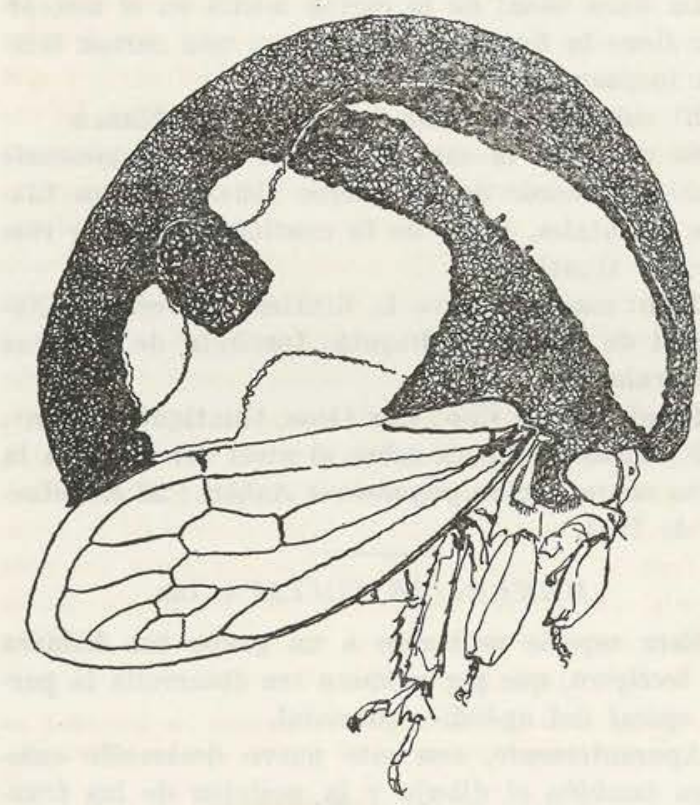

Fig. 32 .

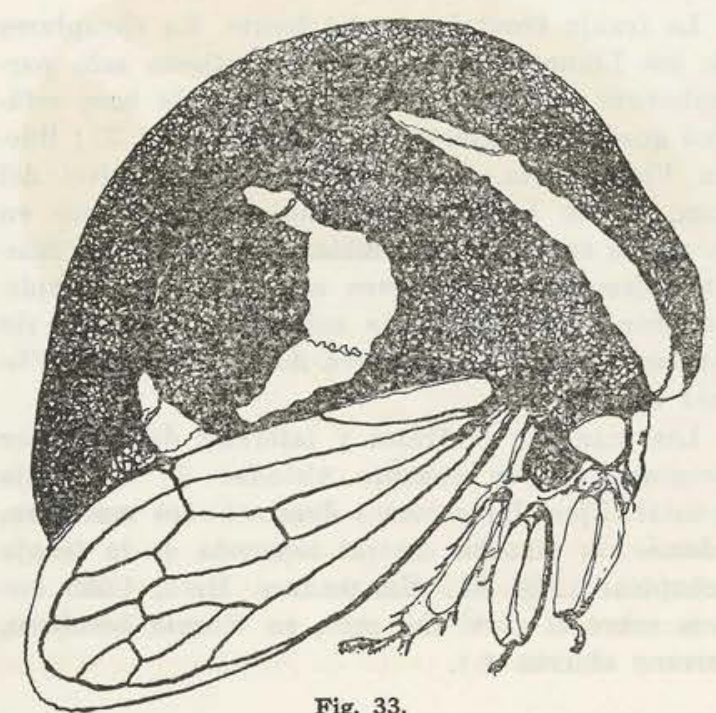

La forma del Amazonas demuestra una vez más la acostumbrada intensificación en tamaño y color de sus franjas laterales. Pero es notable también en este ejemplo que la franja frontal está excluída de esta Gltima transformación.

Lo que corresponde exactamente a las formas que aparecen en tectigera y elevata (véanse Fgs. 17 y 20) de la misma región; también en éstas sólo se expresa la intensificación mencionada en las franjas o manchas laterales y no en la franja frontal.

La larva también tiene las características de tectigera: las espinas dorsales cortas, cónicas y amarillas.

Foliata nunca vive dentro de la selva y tampoco en el valle del Magdalena.

MEMBRACIS TRIMACULATA Fairmaire.

Es la forma foliata del valle del Magdalena y vive allí solamente en la selva.

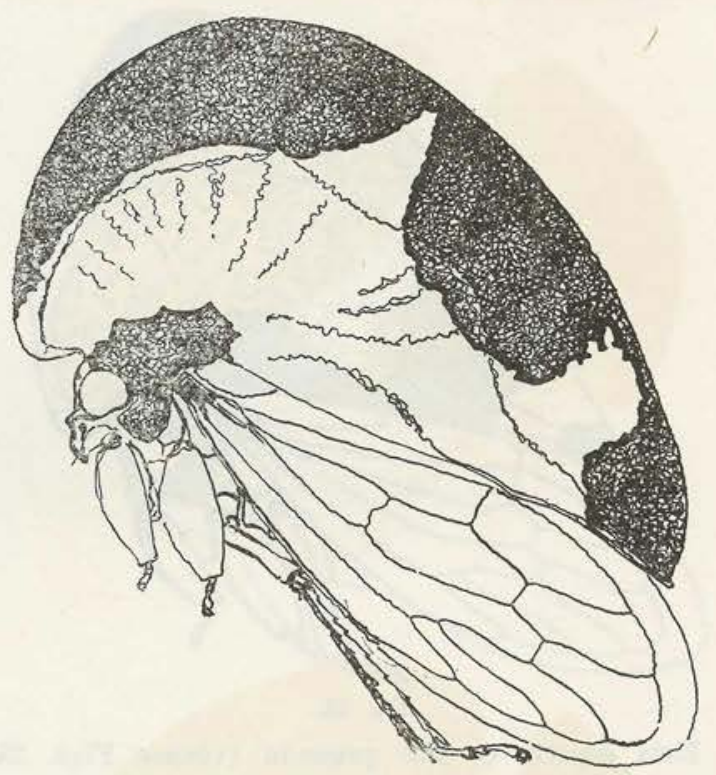

Fig. 34.

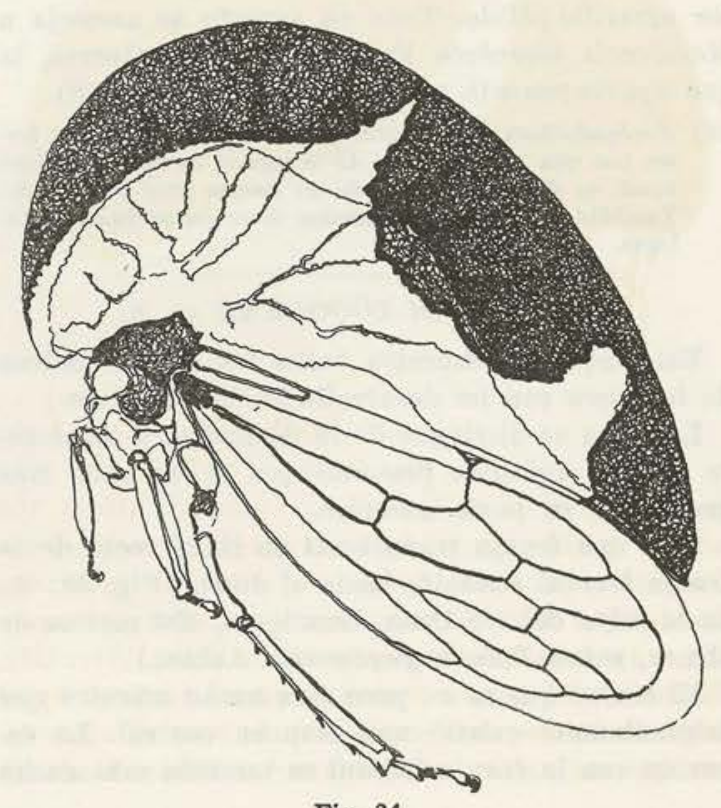

Fig. 34 . 
La franja frontal en esta especie se ha fusionado con las franjas laterales.

Esta fuśión - un paso más en el desarrollo, comparándola con foliata- es la consecuencia necesaria de la prolongación más grande de la parte apical del apéndice pronotal. Así que se nota en realidad una conexión entre el desarrollo del apéndice y el movimiento de todas las franjas.

La línea básica de la carina media en trimaculata y foliata son iguales (Fig. $34: \hat{o}+q$ de las selvas del río Carare, 300 metros de altura).

\section{MEMBRACIS ZONATA Fairmaire.}

Todos los ejemplares procedentes de las selvas de la ladera oriental (400-800 metros de altura sobre el nivel del mar) de la Cordillera Oriental muestran una franja lateral desde el ápice con curva ligeramente convexa hacia el dorso en el metopidio.

La franja subapical cubre todo el ápice (Fig. 35:
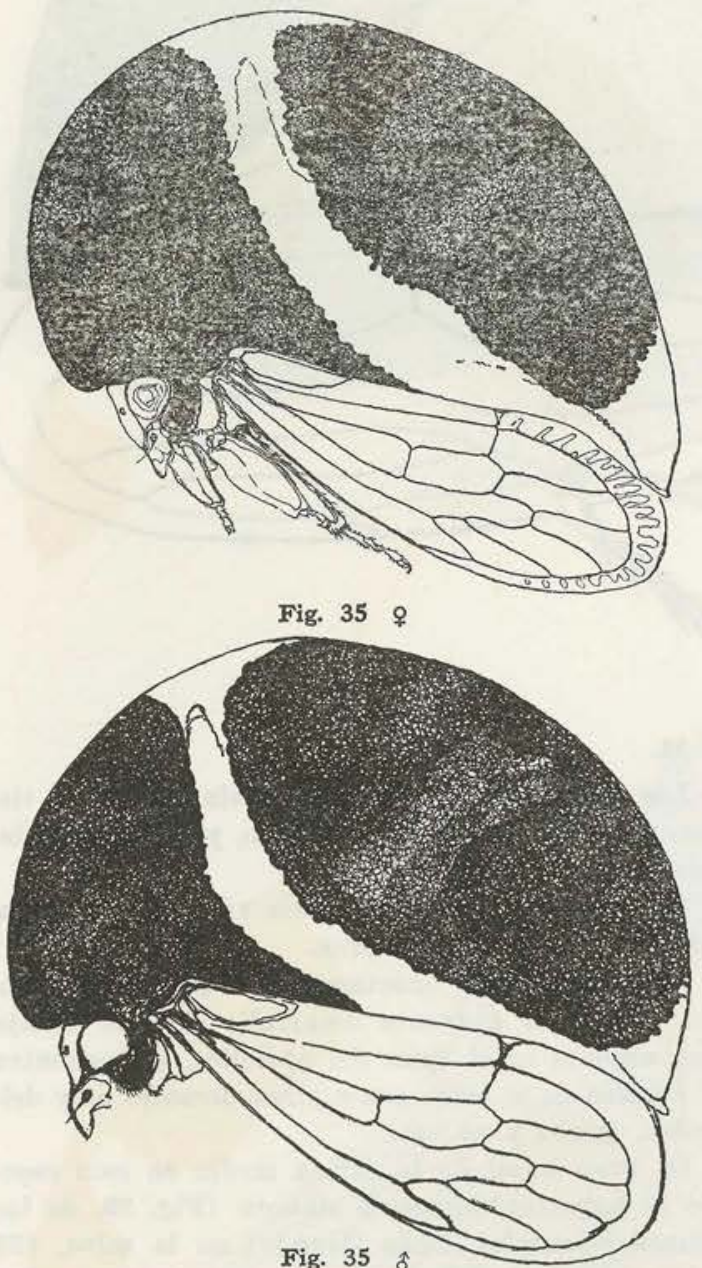

de las selvas en la Cordillera Oriental, altura 700 metros y más cerca de Villavicencio hasta el río Guamal). La parte dorsal de unión de estas dos franjas que están situadas una a cada lado, se muestra muy ensanchada (resto de la franja frontal). El desarrollo parece tomar el curso desde el ápice hacia la frente; esta suposición se basa en ejemplares que no tienen completamente desarrollada la parte situada antes del margen dorsal (Fig. 36, también de las selvas en la Cordillera Oriental).

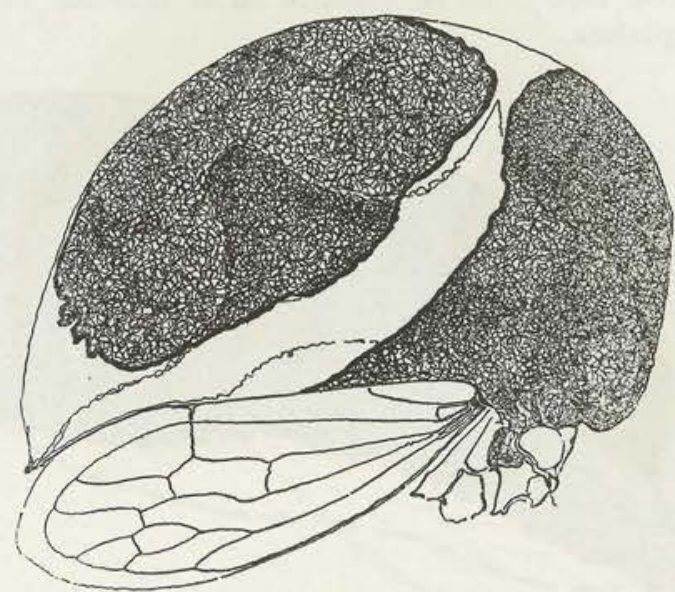

Fig. 36 .

En las espinas dorsales de las larvas se ven además las características del habitus de elevata. La línea básica de la carina media forma dos lóbulos que están relativamente cerca uno del otro, y que han adoptado la forma de grandes cuernos. El del metopidio termina siempre en una punta, mientras que el otro cuerno sobre el subápice está siempre truncado, y a veces muestra una ligera hendidura. La punta del apéndice pronotal mismo (sin carina) que se extiende hacia el apéndice apical, se muestra en esta especie como muy larga.

La misma especie de la región inmediata del río Amazonas (9) se distingue de modo típico por una franja muy recta (Fig. 37, del interior de la selva amazónica, 3 kilómetros de distancia de la orilla) y ha desaparecido hasta el último resto de la franja frontal, lo que coincide de manera clara que esta franja que en elevata ocupa todo el frente, en la forma zonata del Llano es muy reducida $y$ ahora en la del Amazonas ha desaparecido.

(9) Como zona con un contenido máximo de humedad en el aire, especialmente en el interior de las selvas.

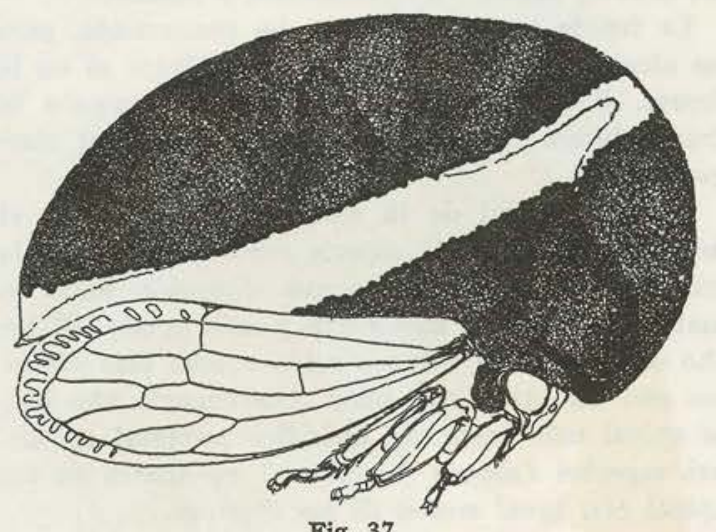

La forma total de los ejemplares del Amazonas vistos lateralmente es semi-elíptica, pero queda constante la línea básica de la carina media.

La especie vive solamente en el interior de la selva y se encontró tanto en los Llanos orientales 


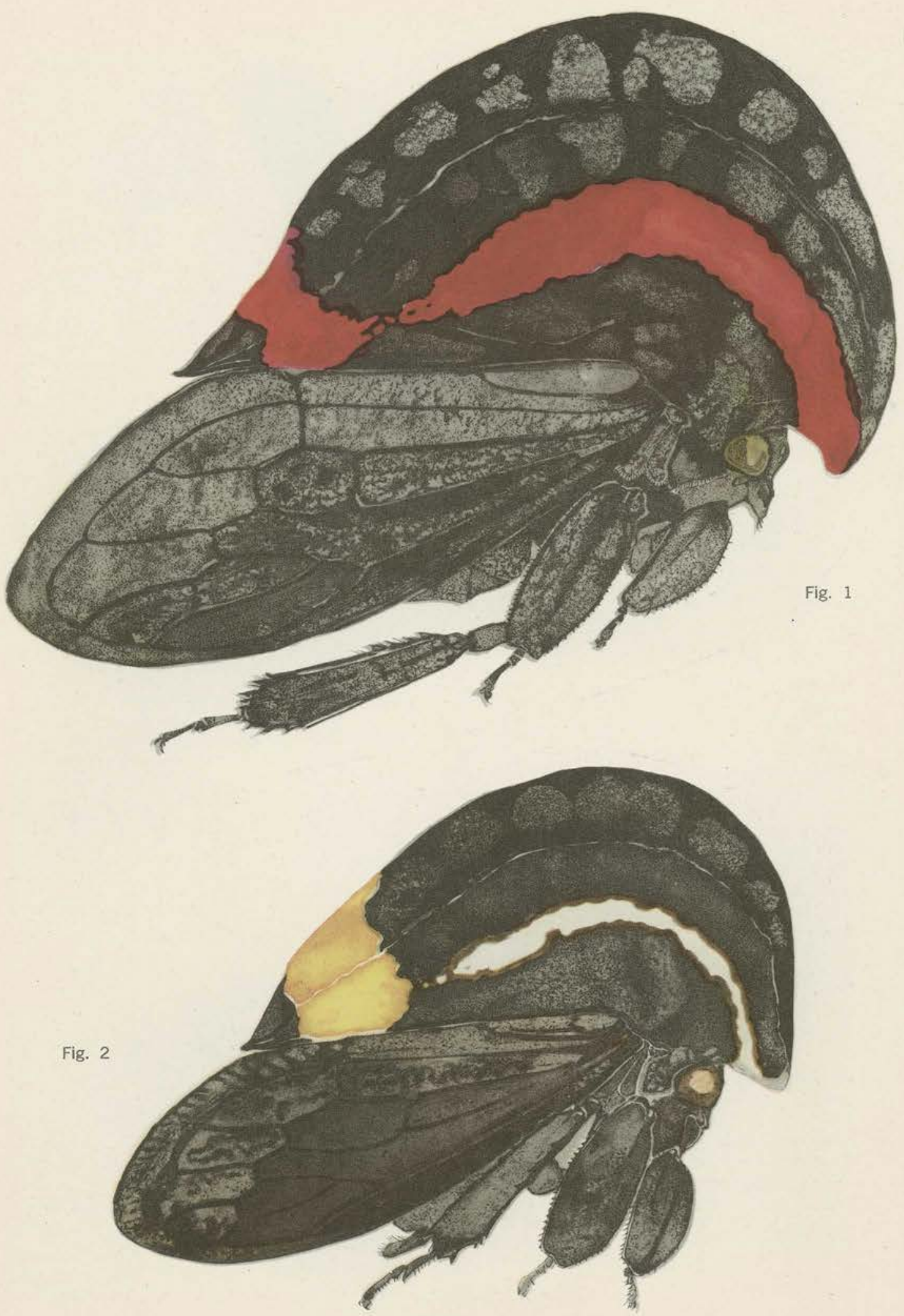

Fig. 1. - Membracis Buctoni Funkh.

Fig. 2. - Membracis Buctoni Funkh.

(Caso único en todo el género Membracis en que las franjas longitudinal y subapical difieren de colorido). (Dib. L. Richter) 
como en la región del río Amazonas sobre Siparuna chiridota Tul.

Esta especie no se encontró en el valle del río Magdalena.
MEMBRACIS ARCUATA Deg.

Es la especie más grande del género y, tal vez, de toda la familia (Fig. 38. De las selvas del río La Miel, cerca al río Magdalena).

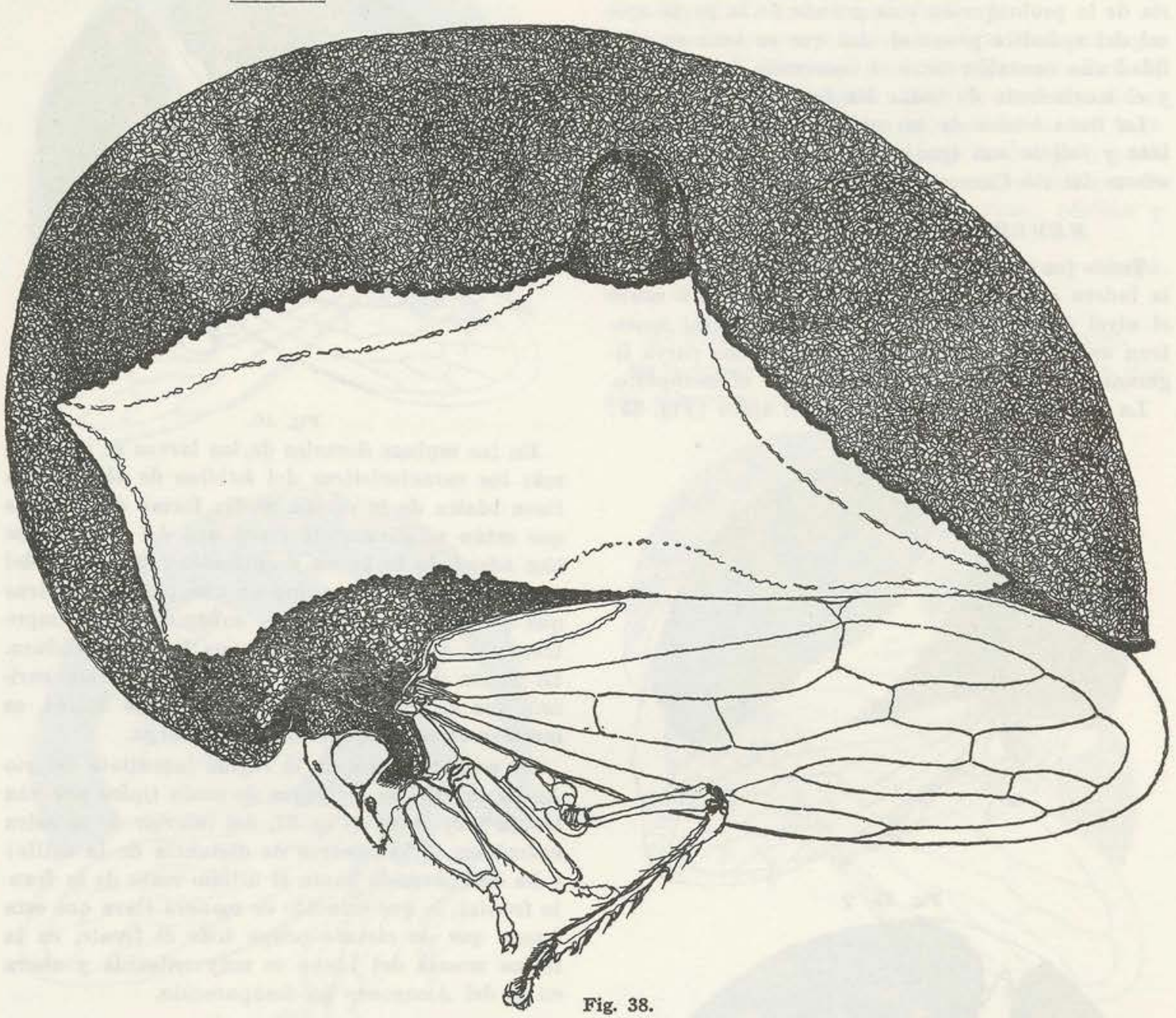

Se podría llamar la especie magdalenense de $M$. zonata, análoga a trimaculata y foliata.

La franja lateral mucho se ha ensanchado, pero no alcanza el borde dorsal ni en el ápice ni en la frente. Solamente como en la especie zonata la franja lateral toca aún la mitad apical del margen lateral.

La línea basal de la carina media muestra el mismo carácter de la especie zonata, solamente la punta anterior, que tiene una dirección hacia el margen frontal, es más corta y más aguda. El hecho de que ambos cuernos estén mucho más distintos uno del otro tiene como consecuencia una parte apical más corta. El apéndice pronotal en ambas especies (zonata $y$ arcuata) encuentra su fin apical casi igual con el de los tégmina.

\section{MEMBRACIS MACULATA Stoll.}

Esta especie fue la única que se encontró - aunque rara vez- en los valles de las pendientes occidentales de la Cordillera Oriental (valle del río Magdalena) y también en los Llanos.
Los ejemplares del Magdalena, sin excepción, tienen todos franjas de color blanco, y los de los Llanos, de color amarillo.

En ambas regiones la especie vive sobre Polygonacea y siempre en la selva.

Correspondiendo exactamente a la franja frontal alta $y$ al aparente desarrollo de una franja que empieza en el ápice del apéndice, se encuentra el habitus de la larva con espinas dorsales muy del. gadas, largas y negras.

La línea basal de la carina media en esta especie es imperceptiblemente sinuosa (Fig. 39, de los Llanos orientales, Caño Grande; en la selva, 450 metros. Fig. 40, del río Opón, en 980 metros sobre el nivel del mar, en la selva sobre Polygonacea).

\section{MEMBRACIS BUCTONI Funkh.}

(Figs. 3 y 4 en la plancha II col.)

La única especie entre las del género Membracis cuya línea basal de la carina media no tiene ninguna ondulación. Esta especie es el ejemplo más 


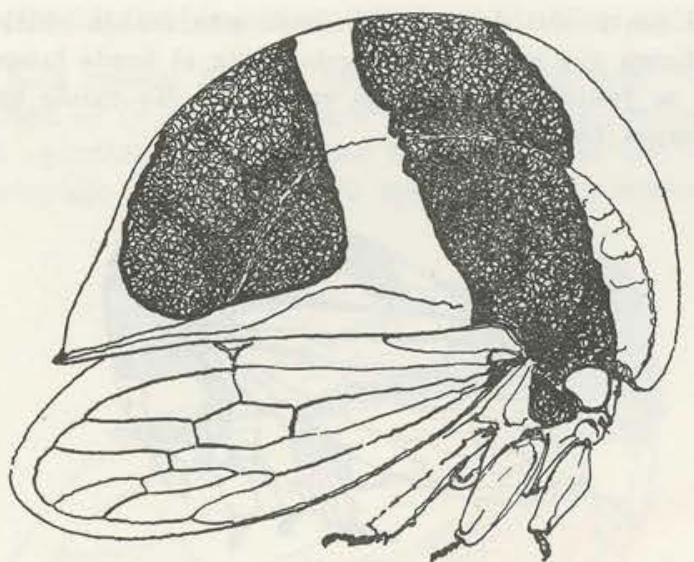

Fig. $39 \hat{~}$

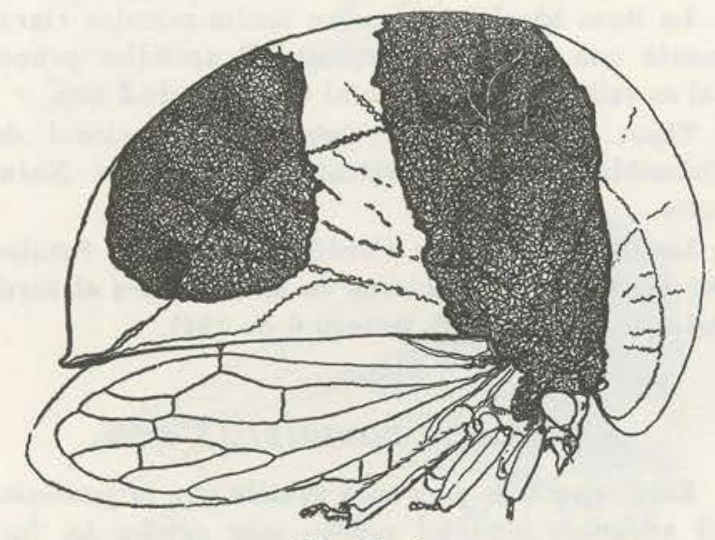

Fig. 39 \%

completo de características extremas y de una absoluta invariabilidad.

La prolongación del apéndice pronotal en la parte frontal llega a tal anchura $y$ longitud que limita la función de los ocelli o la inhibe (en las hembras). (Fig. 41, de las selvas, al pie de la Cordillera Oriental, 450 metros). La franja lateral que pasa por encima de los humerales, correspondiente al habitus de la forma tres o cuatro en tectigera, alcanza el borde frontal sólo encima de la base cefálica, es decir, en la parte interna del margen frontal.

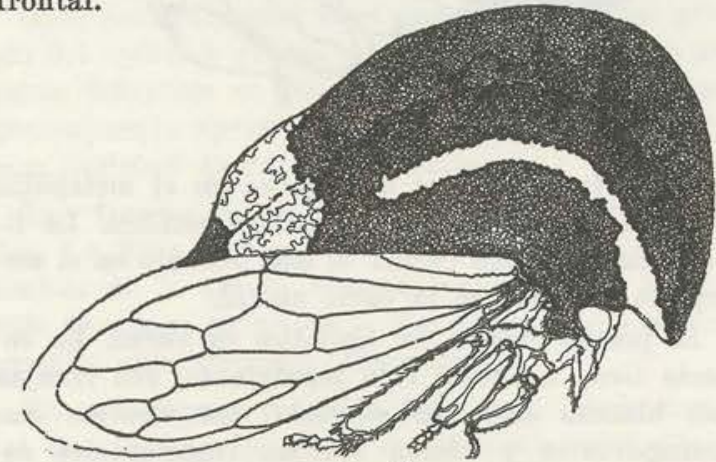

Fig. 41.

No obstante la estabilidad destacada de todas las formas del apéndice pronotal y del cuerpo en total, se pueden observar también en esta especie variaciones en el desarrollo de la franja lateral según el sistema y el habitus de tectígera, lo que prueba

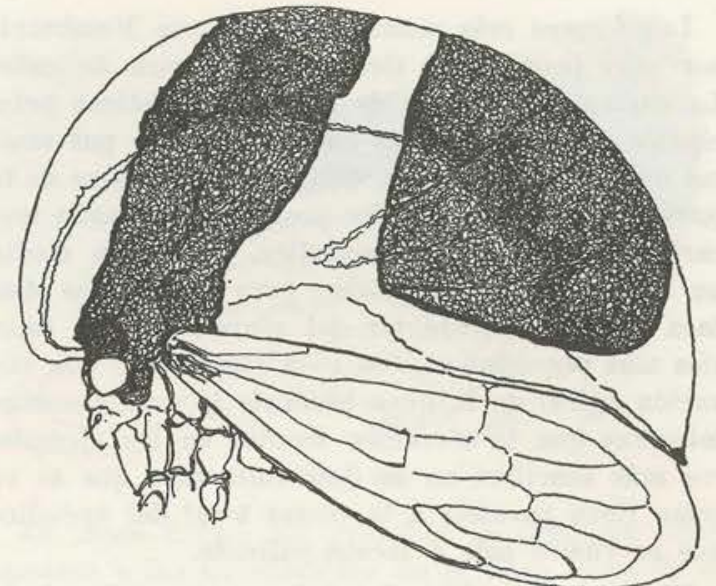

Fig. 40 के

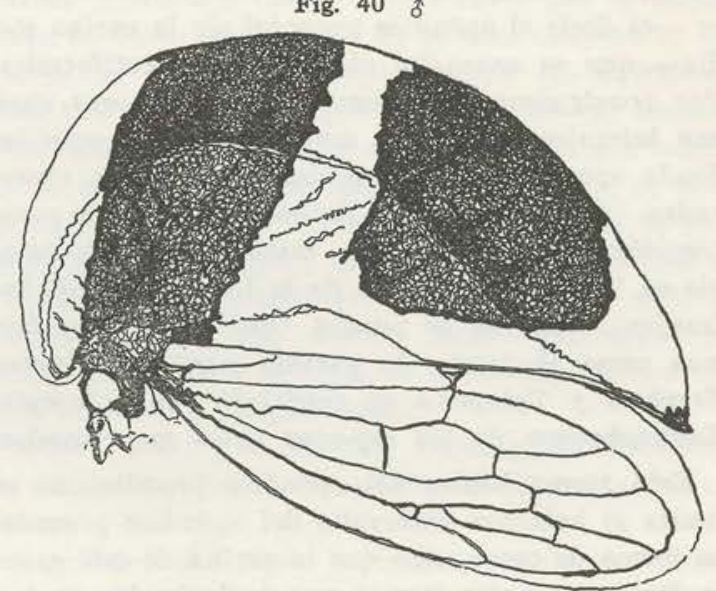

Fig. 40 우

a su vez que: el desarrollo de las franjas es consecuencia de la cantidad alimenticia al alcance del individuo en su estado de larva. Aunque queda constante el alimento $\mathrm{y}$ el ambiente no pueden alcanzar igual cantidad de este alimento por la posición típica que toman los individuos, uno detrás del otro, sobre la nervadura de la hoja. Las diferencias no pueden ser sino muy pequeñas, porque nunca se ha podido observar en esta especie sino tres larvas que vivían juntas. La cantidad de huevos que una hembra de esta especie puede poner, me es desconocida, aunque se puede suponer que tampoco existen diferencias en la deposición de los huevos, la cual se realiza en este género en forma de paquete. La especie vive solamente dentro de la selva sobre una liana que no ha podido ser clasificada por faita de flores.

Las franjas de la especie son en ambos sexos de un rojo profundo mate (color muy extraño en membrácidos). En un solo caso (Fig. No 4 en la plancha II col.) se cogí un macho volando que tenía franja longitudinal blanca $y$ la franja subapical amarilla - el único caso en todo el género $\mathrm{Mem}$ bracis que la franja subapical tiene otro color distinto del blanco, si las demás franjas son blancaslo que hace suponer que la especie ha vivido también en otra planta huésped. 
Las formas más sencillas del género Membracis son muy pequeñas y tienen todas forma de cuña. La carina media, una de sus características principales, generalmente se eleva muy poco por encima de la sutura cefálica, que sale poco a poco de la parte frontal del apéndice pronotal, formando una carina frontal de este apéndice. La carina media no alcanza mayor anchura, pero siempre se destaca dentro del carácter del género. En las especies más pequeñas sólo se nota claramente una elevación apical de la línea basal de la carina media, mientras que la elevación frontal en los ejemplares más sencillos no se desarrolla sino que se ve como línea paralela a la forma total del apéndice que se vuelve más o menos saliente.

Llama la atención el propio cuerpo del apéndice - es decir el apéndice pronotal sin la carina media- que se ensancha rápidamente (tectiformis). Por consiguiente, se muestran las primeras carinas laterales en puntos muy distintos a aquellos donde aparecieron en especies hasta ahora observadas. (Otra distribución del material para la construcción del apéndice, que también se hace notable en la distinta manera de la localización de las franjas). Por eso se pueden considerar estas formas como el punto de partida para los géneros Erechtia y Tylopelta en contraste con LeioscytaEnchophyllum de las especies antes mencionadas.

Esta forma básica del apéndice pronotal no se limita al habitual desarrollo del apéndice pronotal en forma de casco, sino que la carina de este casco se desarrolla hasta formar una prolongación en forma de cuerpo saliente, lo que más tarde y con pocos cambios da el carácter del género Enchophyllum.

Finalmente se encuentra una especie cuyo apéndice en la parte frontal del apéndice pronotal en nada es inferior al cuerno saliente de ciertas especies de Enchophyllum, pero sin mostrar ni rastro de una carina lateral. Este hecho hace menester otra amplificación en las características genéricas de Membracis:

Thorace maxime compresso-elevato, altissimo, dorso summo late vel latiuscule foliacea, anterius a latere viso rotundato vel in cornum breviter producto; plerumque ne anterius quidem in parte dorsali laterali carinula instructo, sed interdum thorace dorso carinis breviter instructo vel saltem cornu antico vel parte antica superiore utrimque carina instructo... Membracis.

El colorido es generalmente de nuevo un pardo denso que parece negro. También se encuentran especies de color gris y otras de color ferruginoso.

\section{MEMBRACIS PAULLULA sp. $\mathrm{n}$.}

El apéndice pronotal tiene forma de cuña, porque la carina media, precisamente, desde el metopidio se angosta rápidamente hasta terminar a cierta distancia de la base cefálica (Fig. 41). Desde el centro del dorso se extiende una franja central blanca que se va angostando hasta el borde lateral y se junta con la franja subapical. No existe una franja frontal.

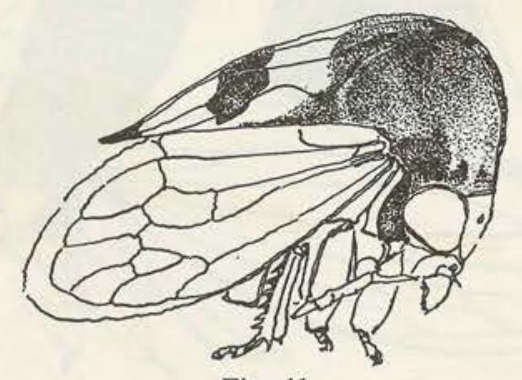

Fig. 41.

La línea basal de la carina media muestra claramente una ondulación apical. El apéndice pronotal es velludo. El largo total es menos de $3 \mathrm{~mm}$.

Tipo: ô L. Richter. Universidad Nacional de Colombia, Bogotá. Instituto de Ciencias Naturales.

Localidad del tipo: Cordillera Oriental, fuentes del río Ocoa, 1.100 metros de altura sobre el nivel del mar, en la selva; febrero 6 de 1941.

\section{MEMBRACIS ROBIGINOSA sp. n.}

Esta especie es poco más grande que la paullula. El apéndice pronotal mucho más agudo. La forma del apéndice pronotal es a manera de casco, un poco cóncavo en la parte frontal (Fig. 42).

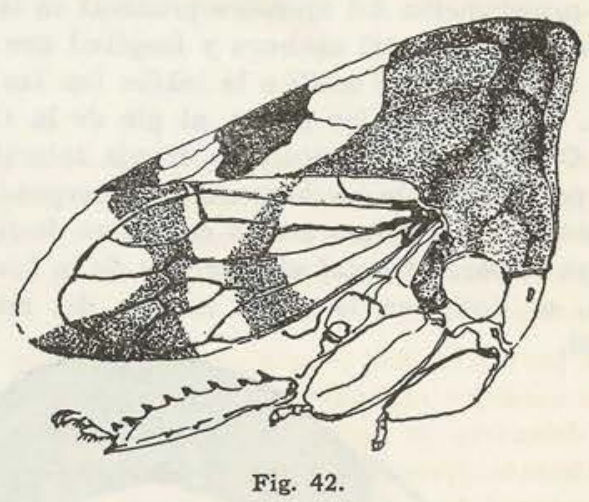

La carina media es más ancha en el metopidio y se va angostando hacia la base cefálica. La linea básica de esta carina es más saliente en el metopidio y menos en la parte apical.

El propio cuerpo del apéndice es ancho. La especie tiene un color rojo ferruginoso, sus franjas son blancas como en paullula; los tégmina son transparentes y tienen franjas transversales oscuras.

Tipo: $ᄋ$ L. Richter. Universidad Nacional de Colombia, Bogotá. Instituto de Ciencias Naturales. Localidad del tipo: Caño Grande (Meta), terreno de H. Eylers; 700 metros; marzo 22 de 1945. 
MEMBRACIS CARINULATA sp. n. (Fig. 43).

Esta especie tiene el apéndice pronotal muy parecido al de paullula, pero es mucho más grande. El apéndice pronotal tiene forma de cuña con el metopidio redondeado $\mathrm{y}$ el ápice se alarga mucho.

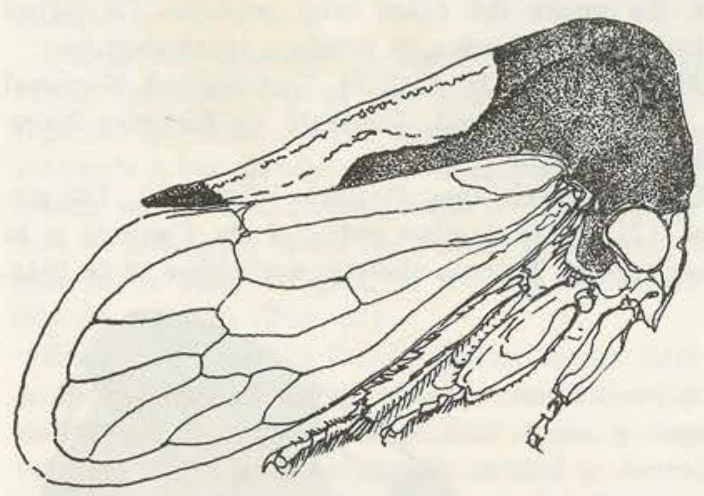

Fig. 43.

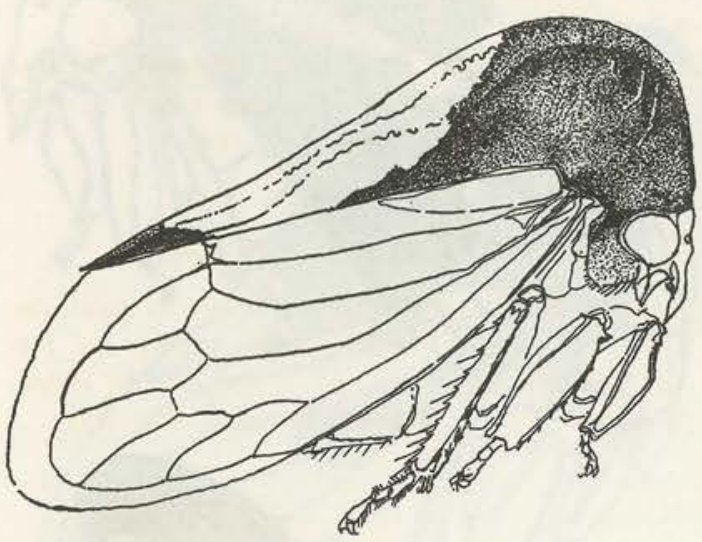

Fig. 43.

La carina media es angosta y se une en el metopidio vagamente con el hundimiento que forma la sutura de una membrana interior (que tienen todas las especies de este género para traer más fácil el apéndice).

Esta particularidad hace aparecer el cuerpo propio del apéndice (apéndice sin carina media) en su parte delantera en forma casi esférica, parte que generalmente (pero no siempre) está cubierta de una cantidad de carinulas débiles.

Las franjas centrales y subapicales están unidas. La línea que marca en dirección cefálica los límites de la franja central originalmente ha tenido la misma forma de la que ya se conoce en las especies anteriormente descritas.

En esta especie también falta una franja frontal. Los tégmina no tienen la célula discoidal situada cerca del borde frontal.

En una región de la misma altura, en Boyacá, más arriba de la carretera entre Tunja y Arcabuco, se encontró un ejemplar (Fig. 44) que tenía separada la mancha central dorsal de la franja subapical.

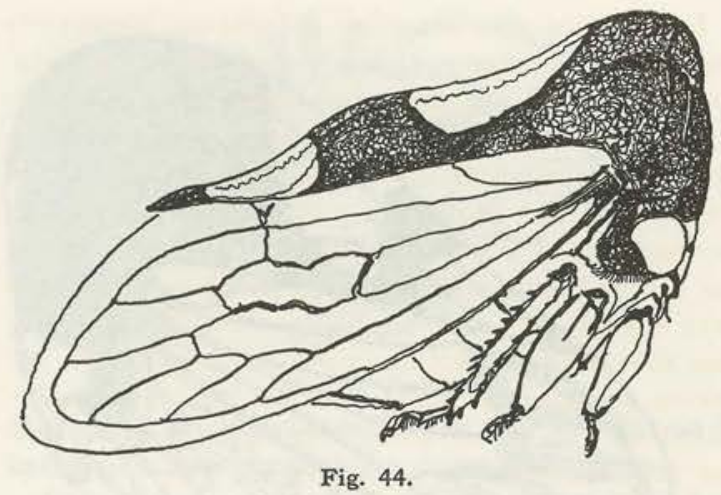

La línea dorsal del apéndice se acomoda exactamente a las ondulaciones de la línea basal de la carina media. La carina media corre por ol dorso para perderse muy arriba de la base cefálica en el plano del frente del propio cuerpo del apéndice. Mientras que en los tipos $(\hat{o}+q)$ eso no sucede sino apenas un poco más arriba de la sutura basal de la cabeza. Sin embargo, parece que sólo se trata de una variedad. Todos estos ejemplares se encontraron en la parte occidental de la Cordillera Oriental a una altura entre 1.900 y 2.100 metros (obsérvase que esta especie tiene solamente una celda discoidal), y se hallaron sobre Eupatorium en una región sin bosque alguno.

Tipo: $\hat{o}+\stackrel{\imath}{\text {; L }}$. Richter, Universidad Nacional de Colombia, Bogotá. Instituto de Ciencias Naturales.

Localidad del tipo: Aguadita, arriba de Fusagasugá (Cundinamarca), 1.900 metros sobre el nivel del mar; en Eupatorium, terreno abierto; febrero 8 de 1945 .

\section{MEMBRACIS FORMOSA sp. n.}

Esta especie tiene la misma forma del apéndice pronotal de carinulata, siendo más alto y más grande el apéndice. La carina media no se pierde en el metopidio, existe la franja frontal y la mancha dorsal está separada de la franja subapical.

El apéndice pronotal tiene forma de cuña, su punta es bastante redonda en el metopidio.

La línea basal de la carina media es ondulada en el ápice; en el metopidio, a igual distancia del margen dorsal, la carina se reduce sólo en el frente y se une muy lejos de la base de la cabeza en el plano que forma el frente (Fig. 45).

La mancha dorsal es triangular, su punta mira hacia el margen lateral con dirección a la franja subapical.

La franja frontal es angosta y se ensancha cerca del metopidio; empieza de la base de la carina media y termina antes de alcanzar el metopidio.

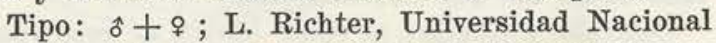
de Colombia, Bogotá. Instituto de Ciencias Naturales.

Localidad del tipo: río Ocoa, selva. 450 metros de altura sobre el nivel del mar, sobre Leguminosa. Junio 5 de 1945. 


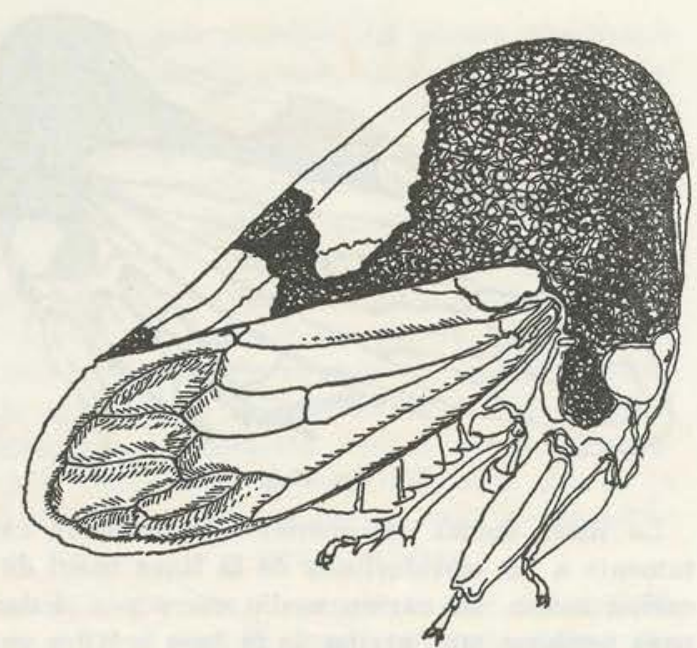

Fig. 45 के

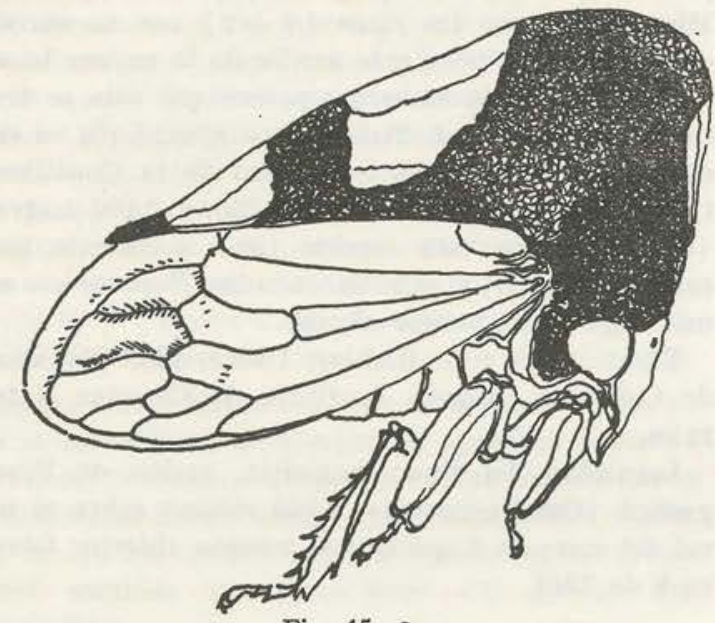

Fig. 45 ㅇ

MEMBRACIS CAQUETAENSIS sp. n.

La especie se distingue de la anterior por el plano frontal que está siempre retrocediendo; el borde dorsal acompaña las ondulaciones de la línea basal de la carina media y así por eso mismo parece ondulado (Fig. 46).

La carina media nace inmediatamente encima de la base cefálica.

Forma del apéndice pronotal: en total tiene forma de cuña y es relativamente poco redondeado en el metopidio. La línea basal de la carina media es más ondulada. La propia carina no llena las ondulaciones de la carina media y por eso parece también ondulada. Muy marcada es la sutura de la membrana interna; además se distingue en las hembras por el colorido de la parte superior del propio cuerpo del apéndice pronotal y de la carina media. El propio cuerpo del apéndice es lateralmente aplastado entre las dos ondulaciones.

Colorido y dibujo: el color básico es negro-pardo; en la hembra, más abajo de la sutura de la membrana interna, blancuzco pardo (como en tectigera sobre Solanum jubatum), y a veces es blanco opaco. La franja frontal nace con la carina por encima de la sutura cefálica y termina ensanchán- dose poco debajo del metopidio. Se manifiesta la tendencia a desarrollarse a lo largo de la sutura de la membrana interna en dirección apical. La especie tiene una franja dorsal blanca que solamente alcanza la sutura de la membrana interna, mientras que está estrechándose. La franja subapical es ancha. La punta del ápice muy pequeña. La mitad apical de los tégmina es pardo y transparente.

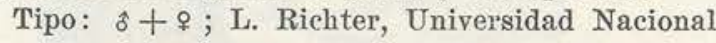
de Colombia, Bogotá. Instituto de Ciencias Naturales.

Localidad del tipo: Pedrera (Caquetá), $180 \mathrm{me}$ tros (?), en el camino entre el río Caquetá y la Base militar. Terreno abierto; noviembre 14 de 1946.
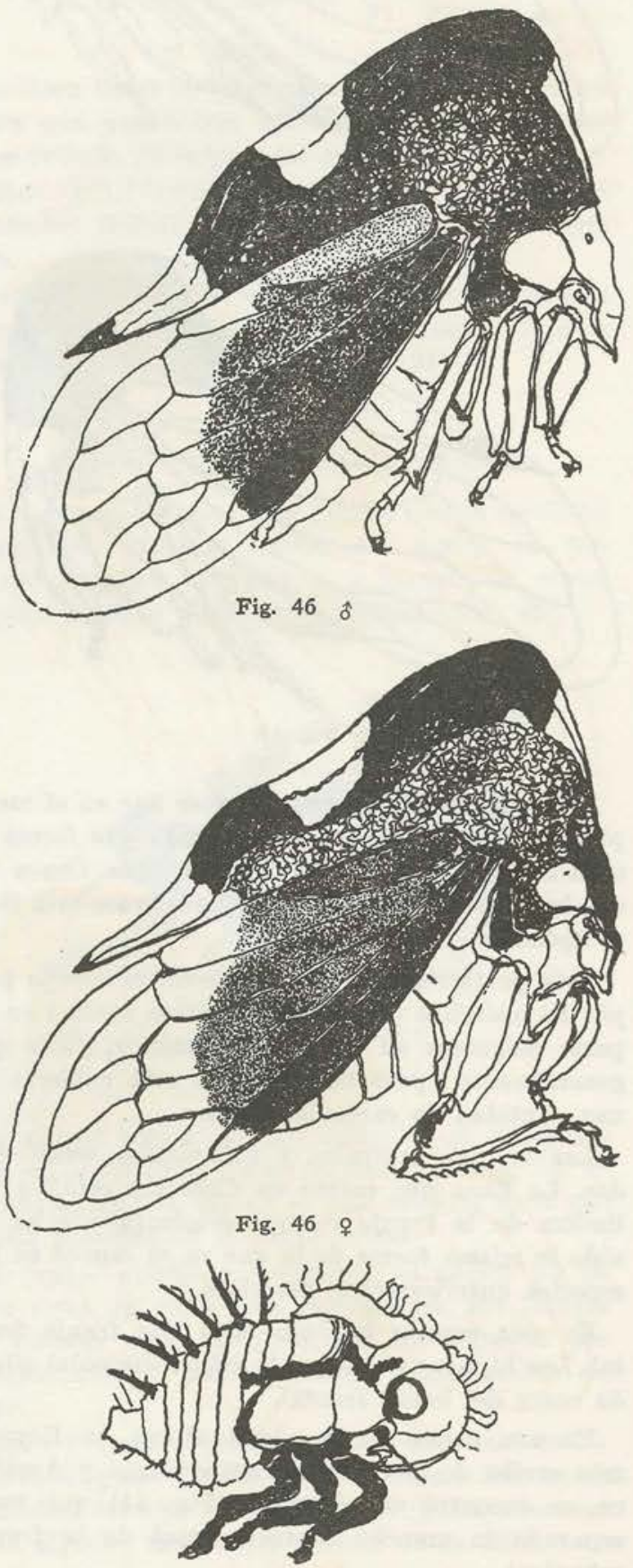

Fig. 46 (larva). 


\section{MEMBRACIS ORTEGUAZAENSIS sp n.}

El aspecto total de esta especie se parece al de formosa. Se distingue de ésta y de otras por franjas o manchas centrales dorsales, por la forma del nacimiento inmediato por encima de la base cefálica, por el dibujo y la forma de la franja central dorsal.

Forma del apéndice pronotal: el apéndice tiene forma de casco, que es más redondeado en el metopidio. La línea dorsal sigue regular, pero visiblemente a las ondulaciones de la línea basal de la carina media. La carina media se prolonga ( $\mathrm{y}$ en esto se difiere de todas las formas anteriores) más allá de la base cefálica, $y$, a veces, sobresale de ella un poquito (Fig. 47).

Color y dibujo: la franja frontal ancha nace en la base cefálica pero no alcanza completamente al metopidio. En la hembra es más ancha y llega a veces al metopidio. La franja central y dorsal se ensancha hacia el margen lateral. La franja subapical deja solamente la punta extrema del apén-

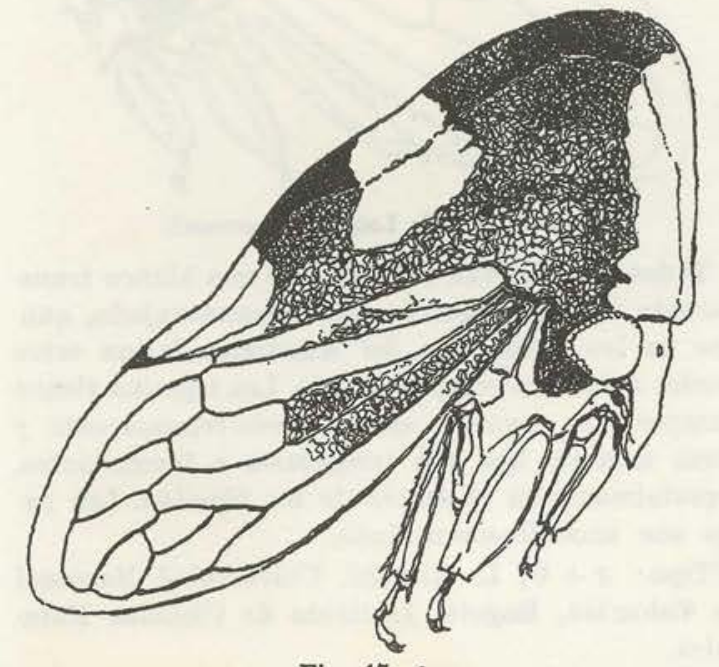

Fig. 47 운

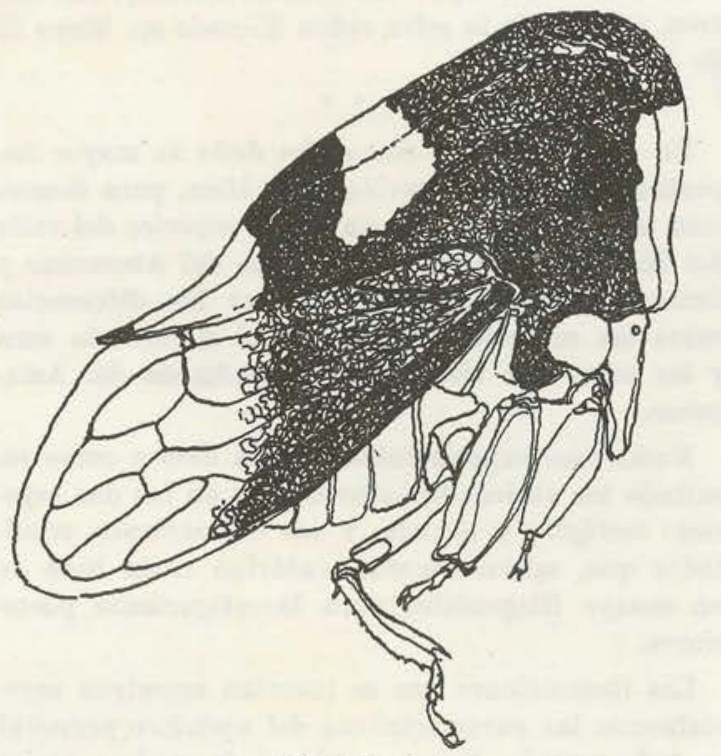

Fig. 47 s

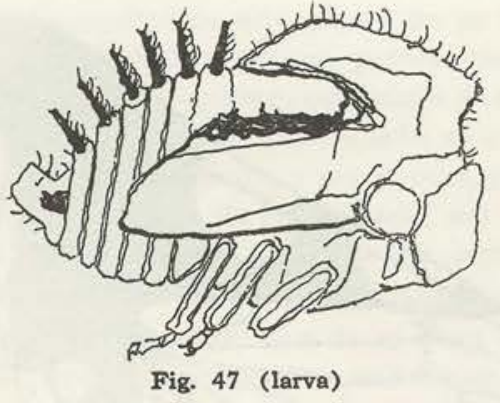

dice negro. El colorido básico es negro-pardo; en la hembra, blancuzco-pardo, a veces muy claro.

En los tégmina la mitad apical o algo más, es pardo-transparente.

Tipo: $\hat{\delta}+\circ$; L. Richter. Universidad Nacional de Colombia, Bogotá. Instituto de Ciencias Naturales.

Localidad del tipo: Base militar: Tres Esquinas, río Orteguaza (alrededor de 200 metros, sobre Inga sp.; terreno abierto (jardín de la Base Militar), marzo 10 de 1946.

Una variedad de esta especie se encontró, igualmente, sobre una leguminosa (Cowelocasia) en el interior de las selvas, sobre el río Ocoa, cerca de Villavicencio. El color de la hembra nunca era más claro que en el macho.

\section{MEMBRACIS SCHULTESII sp. n.}

Esta especie se distingue de todas las anteriores por una prolongación en forma de cuerno en la parte frontal del apéndice pronotal. La línea basal de la carina media sigue exactamente paralela a esta prolongación. La ondulación apical de esta línea basal es muy corta, pero siempre claramente visible.

La carina media sobresale a la base cefálica. La franja frontal se extiende de la base cefálica hasta muy cerca del metopidio; pero en la hembra es más cerca que en el macho.

La franja dorsal es de un ancho igual, redondeado hacia el borde lateral (Fig. 48). La franja subapical es mucho menos ancha.

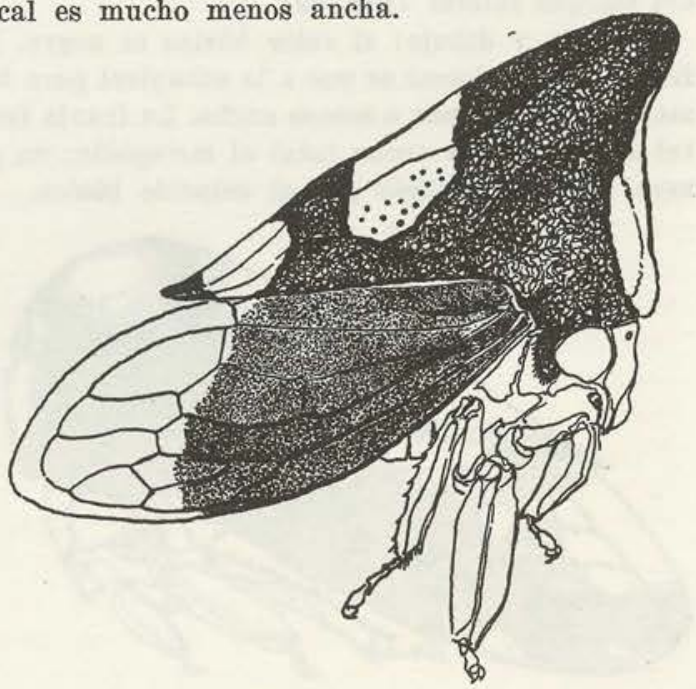

Fig. $48 \hat{o}$ 


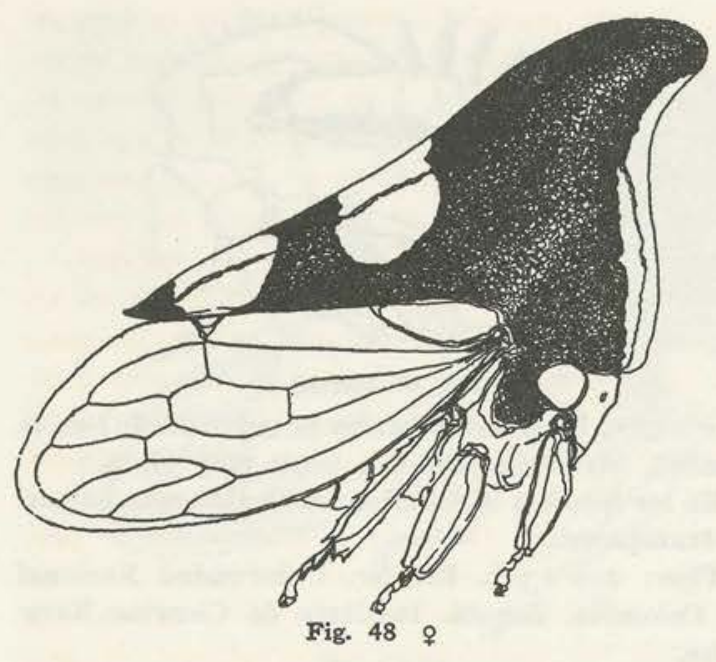

Tipo: $\hat{o}+\stackrel{+}{ }$, L. Richter. Universidad Nacional de Colombia, Bogotá. Instituto de Ciencias Naturales.

Localidad del tipo: Loreto-Yacu (Amazonas), 180 metros sobre el nivel del mar; octubre 7 de 1946.

Esta especie se encontró exactamente en la misma forma sobre los ríos Ocoa y Humadea. En uno de los casos se ve una ligera carínula lateral, pero sólo en un lado del cuerno.

Dediqué esta especie a mi amigo Richard Evans Schultes, explorador incansable de las regiones centrales del río Amazonas.

\section{MEMBRACIS MICANIAAE sp. n.}

Se distingue de todas las anteriores especies porque las ondulaciones metopidiales se destacan fuertemente de la dirección general de la línea basal de la carina media. El apéndice pronotal tiene forma de cuña plana con un metopidio muy redondeado. El cuerpo propio del apéndice es muy ancho.

Encima de cada humeral hay una carina lateral muy corta a igual distancia tanto del dorso como del margen lateral (Fig. 49).

Colorido y dibujo: el color básico es negro. La franja central-dorsal se une a la subapical para formar una franja más o menos ancha. La franja frontal alcanza en su ancho total al metopidio; en general es interrumpido por el colorido básico.

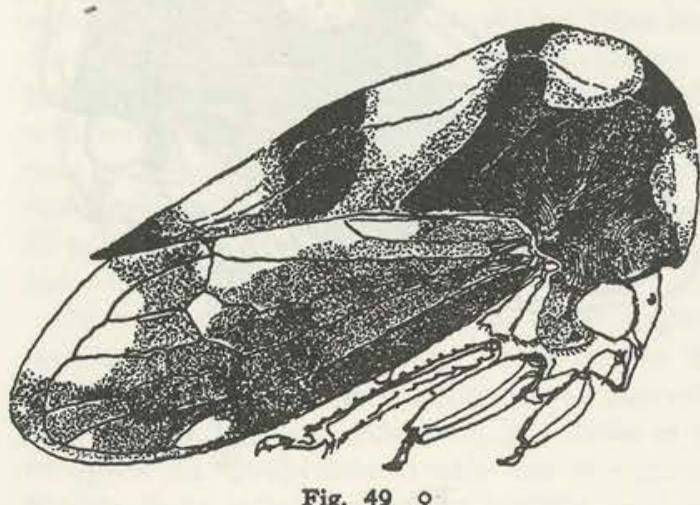

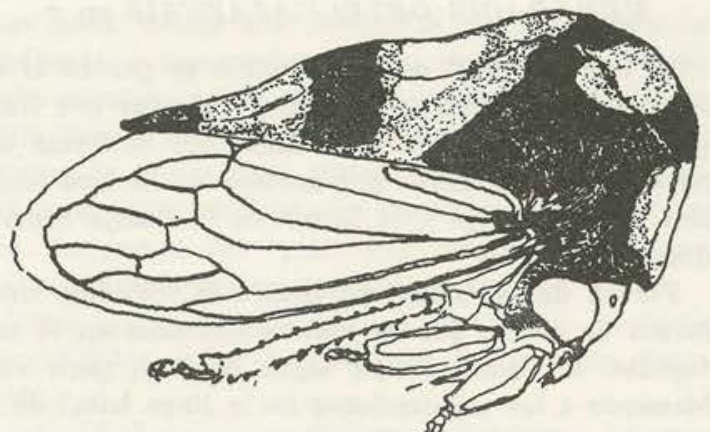

Fig. 49 o

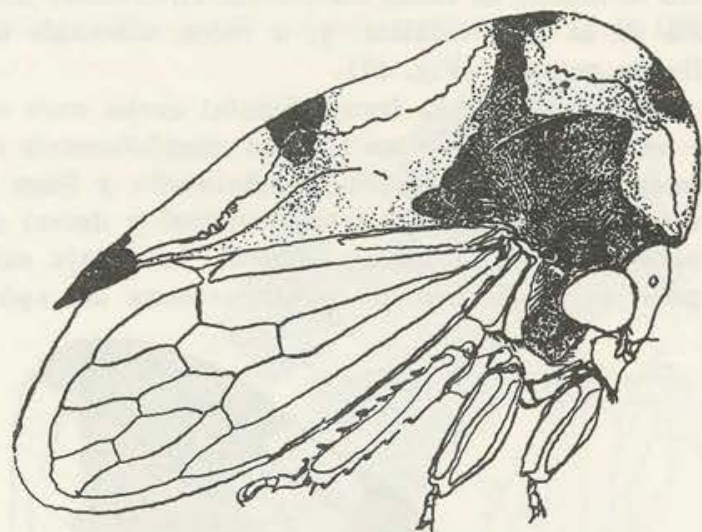

Fig. 49 \% (de Leticia, Amazonas).

Todas las manchas y franjas de una blanco transparente tienen bordes de amarillo-anaranjado, aunque en los ejemplares del Amazonas faltan estos bordes amarillos completamente. Los tégmina tienen siempre una mancha apical pardo-transparente y otras menores que son irregulares e inconstantes, especialmente en el centro de los tégmina. Las patas son amarillo-anaranjado.

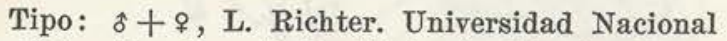
de Colombia, Bogotá. Instituto de Ciencias Naturales.

Localidad del tipo: río Guamal (Meta), 400 metros, margen de la selva sobre Miconia sp. Mayo 25 de 1945.

$$
\text { ** * }
$$

En estas descripciones se ha dado la mayor importancia a la distribución geográfica, para demostrar la separación absoluta de las especies del valle del Magdalena de las de los valles del Amazonas y Orinoco, y además, hacer constar las diferencias entre las especies que pueblan el norte más seco y las otras que viven en el sur húmedo del Amazonas.

Numerosos experimentos de cría dieron como resultado las variedades interesantes de las dos especies: tectigera y elevata, y sus derivaciones, resul. tados que, aparentemente, valdrían como base de un ensayo filogenético para investigaciones posteriores.

Las ilustraciones que se insertan muestran especialmente las características del apéndice pronotal en todo sentido. No se consider 6 de modo especial 
la sutura basal de la cabeza, la posición de los ocelos y detalles de las tibias, porque todas estas características se han mostrado como de un valor taxonómico muy dudoso: por un lado depende del observador (distancia de los ocelos o forma de la sutura basal entre cabeza $\mathbf{y}$ apéndice) y de la interpretación de tales valores, y por el otro lado parece muy incierto, frente a una gran variedad.

La forma de la sutura basal entre cabeza y apéndice está suficientemente visible en la vista lateral de los dibujos, por lo menos en cuanto a la forma real de la curva.

El colorido, especialmente el de los tarsos, no tiene ningún valor taxonómico, porque los colores son consecuencia de la densidad del pigmento. Tarsos hay que pueden parecer de un amarillo claro, y en individuos de la misma cría (hermanos) este amarillo puede aparecer pardo-negro, o totalmente negro, según la densidad del pigmento.
El aparato genital de este género no se tuvo en cuenta como distintivo, porque parece que existe un parentesco íntimo en todas las formas de estas especies, lo que se manifiesta, por un lado, en una gran semejanza entre las especies, y por el otro, una cierta variabilidad dentro de una especie, así que los genitales no dan valores de distinción seguros.

Además, se puede constatar generalmente en los membrácidos lo siguiente: cuando se trata de géneros cuyas especies son grandes saltadores o hábiles voladores, el oedagus, parece siempre el medio más util de distinción entre las especies, aunque éstas sean muy parecidas exteriormente (Tragopa, Cyphonia, Aconophora, Rhexia, etc.) ; pero especies de un temperamento más perezoso, a las cuales pertenece también el género Membracis, muestran el desarrollo correspondiente de este órgano. 